\title{
INFLUENCE OF TRAFFIC MIX ON PCU VALUE OF VEHICLES UNDER HETEROGENEOUS TRAFFIC CONDITIONS
}

\author{
Prema Somanathan Praveen ${ }^{1}$, Venkatachalam Thamizh Arasan ${ }^{2}$ \\ ${ }^{1,2}$ Transportation Engineering Division, Department of Civil Engineering, Indian Institute of Technology \\ Madras, India - 600036
}

Received 29 October 2012; accepted 29 May 2013

\begin{abstract}
Study of the basic traffic flow characteristics like traffic volume is the pre-requisites for the effective planning, design, operation and management of roadway systems. Traffic in developing countries like India is heterogeneous in nature consisting of vehicles of different categories with widely varying dimensional and operational characteristics. The moving vehicles of heterogeneous traffic occupy any convenient lateral position on the road without any lane discipline, based on the availability of space. The interaction between moving vehicles under such traffic condition is highly complex in nature, which can be represented in terms of the amount of impedance caused to flow of traffic by a vehicle type in comparison with that of standard vehicle (passenger car). Passenger Car Unit (PCU) can be an appropriate measure to represent the relative impedance caused by a vehicle in heterogeneous traffic. This paper is concerned with the application micro-simulation technique to derive equivalency values (PCU factors) on a purely homogeneous (cars-only) traffic stream as well as on a heterogeneous traffic stream for different categories of road vehicles over a wide range of traffic flow and compositions on four-lane divided urban roads in India. The PCU values obtained for the different types of vehicles, for a wide range of traffic volume and composition, indicate that the PCU values of a vehicle type significantly changes with change in traffic volume and composition.
\end{abstract}

Keywords: heterogeneous traffic, homogeneous traffic, passenger car unit, simulation model, traffic volume and composition, urban roads.

\section{Introduction}

The traffic stream in developed countries mainly consists of cars and heavy vehicles (buses and trucks). The proportion of heavy vehicles in the traffic stream is generally small and the dynamic characteristics of the heavy vehicles vary marginally from those of cars. The characteristics of traffic flow under such fairly homogeneous traffic conditions, with cars constituting about $80 \%$ or more of the vehicles, displaying lane discipline becomes easily predictable. On the other hand, in developing countries like India, road traffic in general and urban roads traffic in particular, is highly heterogeneous comprising vehicles of widely varying static and dynamic characteristics and the vehicles share the same road space without any segregation. Knowledge of the basic traffic flow characteristics like traffic volume under such heterogeneous conditions is fundamental, since traffic volume is the basic input variable in planning, design and operation of roadway systems.

\footnotetext{
${ }^{2}$ Corresponding author: arasan@iitm.ac.in
} 
Traffic flow under highly homogeneous traffic conditions with cars constituting the major part of the traffic stream, traffic volume can be expressed in terms of number of vehicles passing a given section of road per unit time. Expressing traffic volume as number of vehicles passing a given section of road per unit time will be inappropriate when several types of vehicles with widely varying static and dynamic characteristics are present in the road traffic. The problem of measuring volume of such heterogeneous traffic with cars constituting only about $30 \%$ or less of total vehicles, has been addressed by converting the different types of vehicles into equivalent passenger cars and expressing the volume as Passenger Car Unit (PCU) per hour or Passenger Car Equivalent (PCE) per hour. PCE or PCU values are used as factors to convert a traffic stream composed of different vehicle types into an equivalent traffic stream composed exclusively of passenger cars (reference vehicles). Under homogeneous traffic conditions the volume or capacity may be expressed in terms of PCU per hour per lane. Since the pattern of occupancy of road space by vehicles under heterogeneous traffic condition differs significantly from that of homogeneous traffic, the volume of traffic has to be expressed taking the whole width of roadway as the basis (Arasan and Krishnamurthy, 2008).

In this study, traffic comprising eight different categories of vehicles (buses, trucks, light commercial vehicles, cars, motorised threewheelers, motorised two-wheelers, bicycles and tricycles) with wide ranging static and dynamic characteristics is dealt with. This study is concerned with estimation of PCU values for the different types of vehicles, under homogeneous and heterogeneous traffic conditions on divided urban roads in India, using an indigenously developed simulation model of mixed traffic flow and study of the influence of changes in traffic volume and composition and volume on PCU of the vehicles.

\section{Literature Review}

In the past, various researchers have adopted different approaches for the estimation of Passenger Car Unit (PCU) or Passenger Car Equivalent (PCE) values of vehicles. The bases used for the estimation process are: (i) delay (e.g. Craus et al., 1980), (ii) speed (e.g. Elefteriadou et al., 1997), (iii) density (e.g. Webster and Elefteriadou, 1999), (iv) headway (e.g. Krammes and Crowley, 1986) and (v) queue discharge (e.g. Al-Kaisy et al., 2002). All these studies and their results, however, are not applicable to Indian conditions as these have been carried out under fairly homogeneous traffic conditions.

Werner and Morrall (1976) derived passenger car equivalencies for trucks, buses, and, recreational vehicles by using Walker's method for rolling and mountainous terrains. The effect of grades on passenger car equivalents for different categories of vehicles under various level-of-services (LOS) was estimated using simulation technique. Sensitivity tests conducted using the simulation model indicated that PCEs for trucks, buses, or recreational vehicles at the slower speeds, (less than 50 $\mathrm{km} / \mathrm{h}$ ), increase rapidly as speed decreases; the PCE varies greatly for a small change in speed. Justo and Tuladhar (1984) emphasized the need for adopting the PCU values under mixed traffic condition and proposed PCU values for urban mid-block sections, signalized intersections, and for kerb parking. It was found that the PCU value of a vehicle on mid-block sections is directly proportional to the width and time headway and inversely proportional to the speed of the vehicle. 
Ramanayya (1988) developed a simulation model MORTAB (MOdel for depicting Road TrAffic Behaviour) to study traffic behaviour under mixed traffic conditions and to estimate PCU values for vehicles. The estimated PCU factor for different vehicle categories shows a decreasing trend, as the LOS deteriorated from A to C. A study of passenger car equivalents by Fan (1990) on Pan-Island Expressway, Singapore, revealed that a different set of values to those recommended in the US and UK standards may be more suitable for capacity analysis in Asian countries. For motorcycles, a PCE of 0.4 was found to be more suitable than the value of 0.75 adopted in UK.

Elefteriadou et al. (1997) found PCE values for freeways, two-lane highways, and arterials using simulation. It was indicated that some variables, such as percentage of trucks, do not always have the expected effect on PCE, whereas, other variables, such as vehicle type, are crucial in the calculations. As per the authors, generally, major differences in PCE occurred on longer and steeper grades. There was great variability in PCE values as a function of the weight/ horsepower ratio as well as of vehicle length. Webster and Elefteriadou (1999) also studied the effect of eight highway traffic variables on truck passenger car equivalency (PCE), based on traffic density, using simulation technique. The following inferences were made through the study: PCE value tends to increase with traffic flow, free flow speed, and grade/length of grade; and PCE value tends to decrease with an increase in truck percentage and number of lanes. Chandra and Sikdar (2000) through an empirical study found that for a given road width, an increase in volume level of heterogeneous traffic causes more density on the road resulting in reduced uniform speed of vehicles. The lower speed difference between cars and subject vehicles yield smaller PCU value for the vehicle type.
Al-Kaisy et al. (2002) investigated the effect of heavy vehicles during congestion. A new approach was developed to quantify the effect by deriving passenger car equivalents (PCEs) using Queue-Discharge Flow (QDF) as the equivalency criterion. The methodology was based on the assumption that the fluctuation in QDF capacity observations would be minimal if the traffic stream was uniform and consisted of passenger cars only. The vehicle counts from QDF capacity observations were used to formulate a nonlinear programming problem, where the objective function was to minimize the variation in the QDF capacity. The PCEs were developed so as to minimize the variation in capacity calculations as measured in PCEs. Rongviriyapanich and Suppattrakul (2005) estimated PCU values as the ratio between the headway of car following a car and subject vehicle following a same type of vehicle. The PCE values of motorcycle were estimated for various combinations of passenger car and motorcycle positions on the road space. The PCE of motorcycle obtained from this study was in the range of 0.3 to 0.7 . It was found that the PCE of motorcycle increased when flow rate increased from 10-15 to 15 $20 \mathrm{PCU} /$ minute. However, beyond that level of flow rate PCE of motorcycle consistently decreases with the flow rate. Al-Kaisy et al. (2005) developed a set of PCE factors for heavy vehicles on freeways and multilane highways during congestion. The suggested PCE factors show that effect of trucks on PCU increases as the percent upgrade increases.

Mallikarjuna and Rao (2006) developed PCU factors for trucks, buses and two-wheelers under heterogeneous traffic conditions prevailing on Indian roads using modified cellular automata simulation model. They found that PCE values decrease with increase in the vehicle's proportion in the traffic stream. Arasan and Krishnamurthy (2008) developed PCU 
factors for different categories of vehicles under heterogeneous traffic conditions prevailing on Indian roads using a microscopic simulation model, HETEROSIM. The PCU values for the different types of vehicles, at various volume levels, on four lane divided urban roads were estimated by taking the average stream speed as the measure of performance. In this study it was found that for the traffic composition considered, the PCU value of all categories of vehicles follows an increasing trend from low volume level of about 500 vehicles per hour to high volume level of about 2000 vehicles per hour, and then decreases at higher volume level of about 4000 vehicles per hour. Geistefeldt (2009) developed a new method for estimating passenger car equivalents for heavy vehicles on freeways. The proposed approach was based on the concept of stochastic capacities. Capacity-distribution function was estimated in passenger car units. Passenger Car Equivalent was determined for which the variance of the capacity distribution function becomes minimal. The suggested PCEs tend to decrease with an increasing number of lanes. The highest PCE was estimated for an uphill section.

Arasan and Arkatkar (2010) studied the variation of $\mathrm{PCU}$ values for a wide range of traffic volume and roadway conditions for different categories of vehicles under heterogeneous traffic conditions prevailing on Indian intercity roads using microscopic simulation. It was found that in the case of vehicles that are larger than passenger cars, at low volume levels, the PCU value decreases with increase in traffic volume and at high traffic volume levels, the PCU value increases with increase in traffic volume. Whereas, in the case of vehicles that are smaller than passenger cars, at low volume levels, the PCU value increases with increase in traffic volume and at high volume levels, the PCU value decreases with increase in traffic volume.
Bains et al. (2012) evaluated the effect of vehicle composition (heavy vehicles and light commercial vehicles) on PCU values at different volume levels, to a limited extent, on expressways in India. PCU values were evaluated using the micro-simulation model, VISSIM. It was found that PCU decreases with increase in volume-capacity ratio and proportion of subject vehicles irrespective of vehicle category. The effect of heterogeneity in terms of vehicle composition in the traffic stream was not accounted for in this study.

The review of literature on the subject matter reveals that studies conducted are mostly related to fairly homogeneous traffic conditions, and the few studies conducted under heterogeneous traffic conditions are not comprehensive enough to replicate the field conditions accurately. Though there are several factors influencing the PCU value of a vehicle type, for a given roadway, traffic volume and composition are the important factors influencing the amount of interaction between vehicles in a traffic stream, and hence the PCU values for the different types of vehicles. Indian Roads Congress (IRC), the professional organisation responsible for development of codes and guidelines related to road transportation in India, has provided a single set of constant PCU values for different vehicle categories (IRC: 106-1990), which are based on limited field observed data. Out of the two factors, namely volume and composition, the Indian Roads Congress has considered the effect of traffic composition only to a limited extent, and has recommended, based on field observed traffic data, PCU values for different types of vehicles on Indian roads for only two levels of composition of subject vehicles. These guidelines for PCU values of vehicles of heterogeneous traffic are based on limited studies, and hence, there is a need to accurately estimate the PCU values through 
comprehensive study of the interaction between vehicles in the traffic. The study proposed here is concerned with estimation of PCU values for the different types of vehicles present in the heterogeneous traffic on Indian roads, through traffic simulation, and study of the influence of changes in traffic composition and traffic volume on PCU of the vehicles.

\section{Scope and Objectives}

The flow of road traffic is generally expressed in terms of Passenger Car Units passing through a roadway sector per unit interval of time. The influence of roadway and traffic characteristics affecting vehicular movement has to be studied at micro level for enabling accurate estimation of PCU values. Accordingly, a heterogeneous traffic-flow simulation model was used to study the traffic flow characteristics for varying roadway and traffic conditions. The research work reported here basically aims at analyzing the characteristics of the heterogeneous traffic flow to identify appropriate theoretical distributions for various traffic variables influencing the traffic stream characteristics, and study of the flow characteristics including quantification of in terms of PCU at vehicular interactions at micro level. PCU estimates of the different types of vehicles have also been estimated to serve as base values for comparison. Finally, a check for the accuracy of the estimated PCU values is also made.

The specific objectives of the research work are as follows:

- To quantify the relative impedance caused to traffic flow by the different categories of vehicles in homogenous and heterogeneous traffic in terms of PCU, using an appropriate micro simulation model;

- To study the possible variation of
PCU values of different categories of vehicles with emphasis on traffic volume and composition and volume under heterogeneous traffic conditions prevailing on Indian urban roads.

\section{Simulation Model}

The fundamental reason for using simulation technique in traffic flow studies is that traffic flow is a highly complex phenomenon and is difficult to understand and analyze by simple mathematical techniques. A simulation model is the imitation of the operation of a realworld process or system over time. Once developed and validated, the model can be used to investigate a wide variety of "what - if" questions about the real world system (Banks et al., 2004). It facilitates the system planner to study and evaluate the performance of transport-network systems at various possible operating conditions. Also, it is possible to take into account the influencing variables comprehensively (Arasan and Krishnamurthy, 2008; Mallikarjuna and Rao, 2006).

Under the heterogeneous traffic conditions prevailing in India, the vehicles occupy any part of the road, based on space availability, without any lane discipline. Hence, the available traffic-simulation models, which are based on homogeneous traffic conditions, where clear lane and queue discipline exists, are not applicable to study the heterogeneous traffic flow characteristics. Also, the research attempts made to model heterogeneous traffic flow (Ramanayya, 1988; Kumar and Rao, 1996; Marwah and Singh, 2000) are limited in scope and do not address all the aspects comprehensively. Hence, an appropriate simulation model of heterogeneous traffic flow named, HETEROSIM, was developed (Arasan and Koshy, 2005). The modeling framework is explained briefly here to provide the background for the study. 
For the purpose of simulation, the entire road space is considered as single unit and the vehicles are represented as rectangular blocks on the road space, the length and breadth of the blocks representing respectively, the overall length and the overall breadth of the vehicles. The front left corner of the rectangular block is taken as the reference point, and the position of vehicles on the road space is identified based on the coordinates of the reference point with respect to an origin chosen at a convenient location on the space. The simulation model uses the interval scanning technique with fixed increment of time. For the purpose of simulation, the length of road stretch as well as the road width can be varied as per user specification. The model was implemented in $\mathrm{C}++$ programming language with modular software design. The simulation process consists of the following major sequential steps related to traffic flow on mid-block sections of roads: (1) vehicle generation, (2) vehicle placement, and (3) vehicle movement. The model is also capable of displaying the animation of simulated traffic flow through mid block sections. The animation module of the simulation model displays the model's operational behavior graphically during the simulation runs. The flow diagram illustrating the basic logical aspects involved in the program is shown in Fig. 1. The snapshot of animation of traffic flow, obtained using the animation module of HETEROSIM, is shown in Fig. 2. The model has been applied for a wide range of traffic conditions (free flow to congested flow conditions) and has been found to replicate the field observed traffic flow to a satisfactory extent through an earlier study (Arasan and Koshy, 2005).

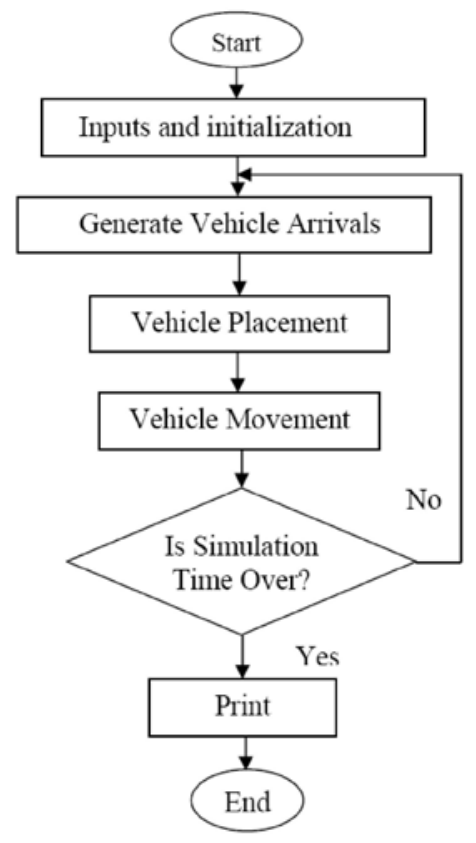

Fig. 1.

Flow Diagram of the Simulation Model 


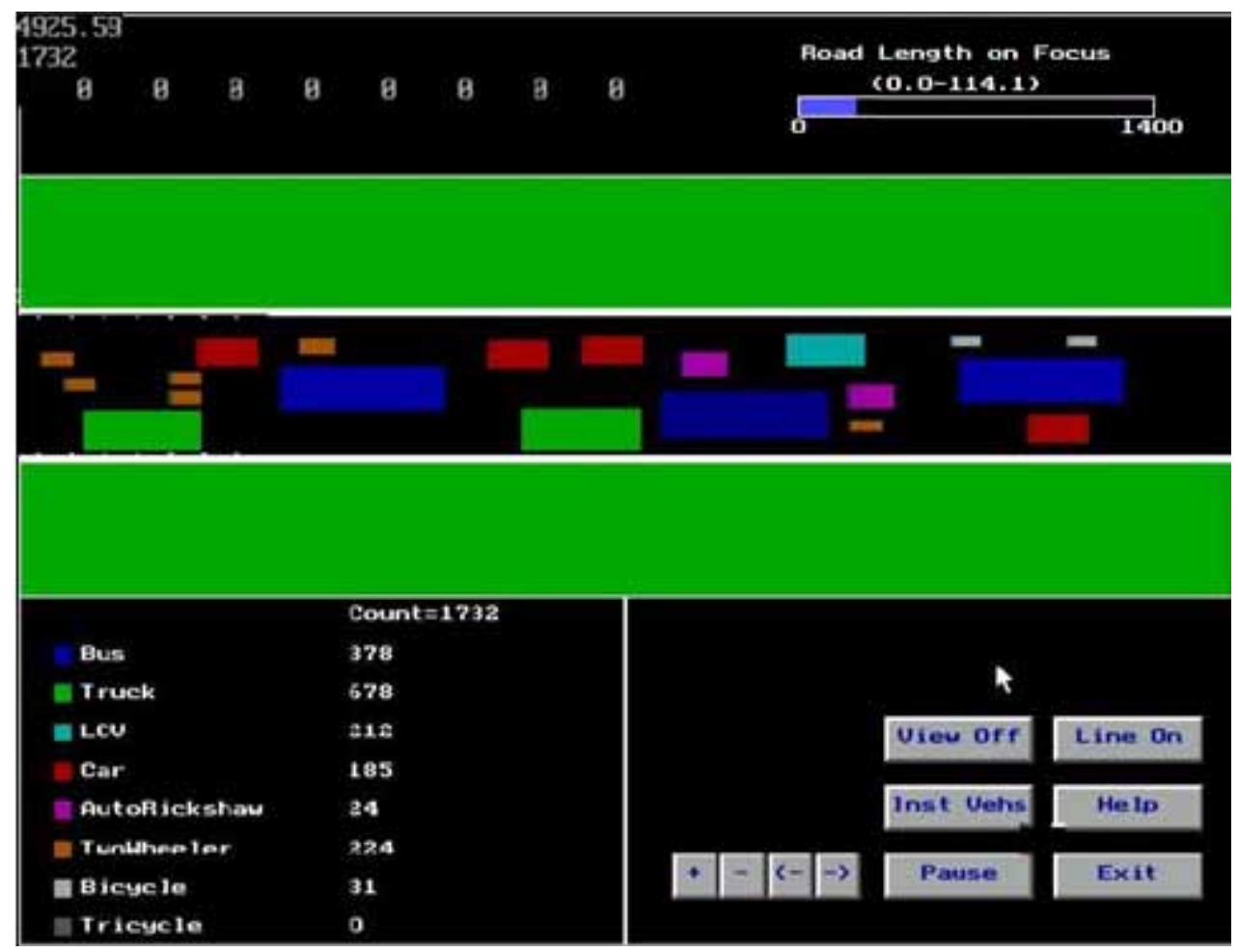

Fig. 2.

Snapshot of Animation of Simulated Heterogeneous Traffic Flow

\subsection{Input Variables}

The input variables required for a traffic simulation model may be divided into four categories: road geometrics, traffic characteristics, driver behaviour and vehicle performance. The important geometric variables are: road width, curvature, grade, sight distance, etc. The three fundamental characteristics of traffic movement- speed, volume and density, define the operational requirements of the traffic stream. The transverse and longitudinal distributions of vehicles on the simulated system may be described in terms of either volume or density. The longitudinal placement of vehicle in the traffic stream affects the driver's choice of speed. The principal characteristics of traffic concern the abilities, requirements, and performance of the driver and the vehicle, which together form the discrete unit of the simulation model. The power of simulation as a tool for the study of traffic flow lies in the ability to include the effect of the random nature of traffic. Hence, the random variables associated with traffic flow, are expressed as frequency distributions and input into the simulation model.

The observed maximum and minimum free speeds of various classes of vehicles and the respective standard deviations are shown in columns (2), (3) and (4) of Table 1. 
The overall dimensions of all categories of vehicles, adopted from literature, are shown in columns (6) and (7) of Table 1. Traffic-simulation model can incorporate acceleration characteristics of vehicles as a necessary input. Hence, acceleration values, for each of the vehicle types constituting the heterogeneous traffic, were taken from the available literature for use in the simulation model. Any vehicle moving in a traffic stream has to maintain sufficient transverse clearances on the left and right sides with respect to other vehicles/curb/median to avoid side friction. These values as taken from an earlier study (Arasan and Krishnamurthy, 2008) are given in columns (8) and (9) of Table 1.

\subsection{Data Collection}

A simulation model requires data from the related real world system for specifying the various input parameters of the model and also for the validation and calibration of the model, since the effectiveness of a simulation model in replicating the real world system depends on the model input data and the means by which they are represented in the model. The data on vehicular characteristics that are required as input to the model were collected from the available literature (Arasan and Krishnamurthy, 2008). The data on traffic flow characteristics were collected in the field by choosing a mid-block section of a road for the purpose. The traffic data was collected by observing the traffic flow on the bridge on Anna-Arch Road, near Kilpauk, which falls in the northern part of the metropolitan area of Chennai city, India. The traffic flow was recorded using a video camera, mounted at a vantage point on the terrace of an adjacent building, which enabled recording of all the traffic flow characteristics (volume composition and speed) at the same time. The video data was then transferred to a computer for further processing. A total of 3599 vehicles were observed (moving in one direction) to pass through the section during the observation period of one hour. The different types of motor vehicles observed on the road stretch were: Buses, Trucks, Light Commercial Vehicles (L.C.V.),

\section{Table 1}

Input Data for Heterogeneous Traffic Flow Simulation

\begin{tabular}{|c|c|c|c|c|c|c|c|c|}
\hline \multirow{2}{*}{$\begin{array}{l}\text { Vehicle } \\
\text { category } \\
(1)\end{array}$} & \multicolumn{4}{|c|}{$\begin{array}{l}\text { Free speed statistics } \\
\qquad(\mathbf{k m} / \mathbf{h})\end{array}$} & \multicolumn{2}{|c|}{$\begin{array}{c}\text { Vehicle } \\
\text { dimensions }^{* *}(\mathbf{m})\end{array}$} & \multicolumn{2}{|c|}{$\begin{array}{c}\text { Lateral clearance } \\
\text { share }(\mathbf{m})\end{array}$} \\
\hline & $\begin{array}{c}\text { Max. } \\
\text { speed } \\
(2) \\
\end{array}$ & $\begin{array}{c}\text { Min. } \\
\text { speed } \\
(3) \\
\end{array}$ & $\begin{array}{l}\text { Std. dev. } \\
\text { (4) }\end{array}$ & $\begin{array}{c}\text { Mean } \\
(5)\end{array}$ & $\begin{array}{l}\text { Length } \\
\text { (6) }\end{array}$ & $\begin{array}{l}\text { Width } \\
(7)\end{array}$ & $\begin{array}{l}\text { Min. } \\
(8)\end{array}$ & $\begin{array}{l}\text { Max. } \\
(9)\end{array}$ \\
\hline Trucks & 65.3 & 40.1 & 6.9 & 51.3 & 7.5 & 2.5 & 0.3 & 0.6 \\
\hline Buses & 54.5 & 41.3 & 7.6 & 54.5 & 10.3 & 2.5 & 0.3 & 0.6 \\
\hline Cars & 86.3 & 45.5 & 10.7 & 63.7 & 4.0 & 1.6 & 0.3 & 0.5 \\
\hline L.C.V.* & 73.3 & 41.7 & 9.4 & 57.2 & 5.0 & 2.0 & 0.3 & 0.5 \\
\hline M.T.W.* & 77.3 & 36.6 & 9.2 & 54.0 & 1.8 & 0.6 & 0.1 & 0.3 \\
\hline M.Th.W.* & 59.1 & 32.4 & 6.7 & 46.5 & 2.6 & 1.4 & 0.2 & 0.4 \\
\hline Bicycles & 21.9 & 11.1 & 3.2 & 16.2 & 1.9 & 0.5 & 0.1 & 0.3 \\
\hline
\end{tabular}

${ }^{*}$ L.C.V. - Light Commercial Vehicles, M.Th.W. - Motorized Three-Wheelers, M.T.W. - Motorized Two-Wheelers

${ }^{* *}$ Average overall dimensions of the vehicles 
which includes large passenger vans and small goods vehicles; Motorised Three-Wheelers (M.Th.W.), which includes Auto-Rickshaws and three wheeled goods vehicles; Motorised Two-Wheelers (M.T.W), which includes Motorcycles, Scooters and Mopeds; Bicycles and Tricycles. It was found during the traffic count that, trucks and tricycles constituted respectively 0.11 and 0.31 percent of the vehicles. The percentages being very small for the purpose of simulation, the trucks which are similar to buses in respect of size and speed, were considered as buses and each of the tricycles, which are similar to bicycle in dynamic characteristics, were considered to be equivalent to two bicycles. The observed composition of the traffic after the above said modifications is depicted in Fig. 3. In the simulation process, the generated vehicle will be placed at the start of the simulation stretch after assigning the free speed of that vehicle type. The free speed data was collected at the study stretch during lean traffic periods when the vehicles were freely moving without any hindrance from other vehicles present on the road.

\subsection{Model Calibration}

There are several probability distributions available to describe the vehicle arrival pattern and headway distribution of traffic flow. In this study, Poisson distribution and Negative exponential distributions were found to fit well for vehicle arrival pattern and headway distribution, respectively. The Chi-square goodness-of-fit test shows that observed frequencies have significant fit with Poisson distribution for vehicle arrival pattern. The calculated chi-square value is 17.647 against the critical value from chisquare table for 11 degrees of freedom at $5 \%$ level of significance of 19.68 . Thus, it was found that, the calculated chi-square value is less than the table value as shown in Table 2, which confirms the goodness-of-fit.

The grouped headway data with a class interval of $1.4 \mathrm{~s}$, was found to fit into Negative Exponential distribution, using chi-square test. The calculated chi-square value is 6.447 which is less than the critical value from chi-square table for 3 degrees of freedom at $5 \%$ level of significance of 7.81 and this confirms the goodness-of-fit. The details of the $\chi^{2}$ test are given in Table 3 . The cumulative frequency of the field observed and theoretical headways, plotted on the same set of axes, is shown in Fig. 4. It can be seen that both are matching with each other well.

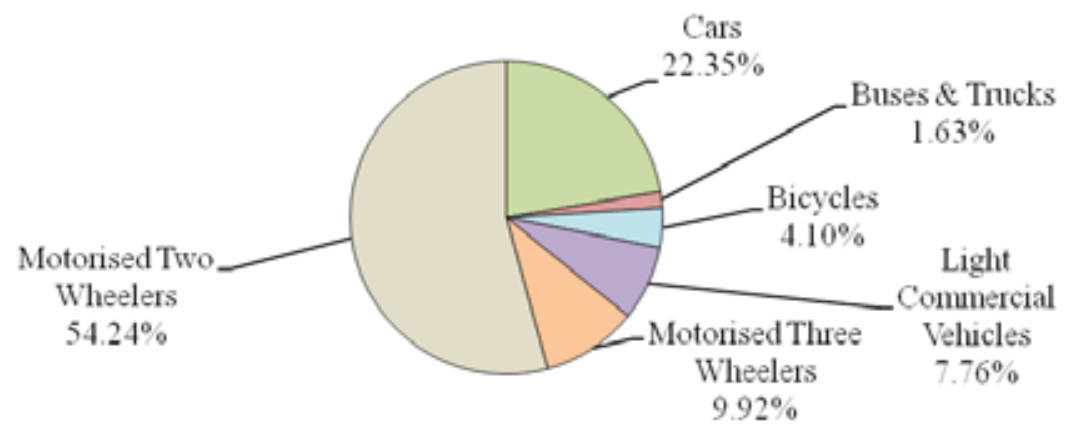

Fig. 3.

Observed Traffic Composition 


\section{Table 2}

Goodness-of-Fit Test for Vehicle Arrival Pattern

\begin{tabular}{|c|c|c|c|c|c|c|}
\hline $\begin{array}{l}\text { No. of vehicle } \\
\text { arrivals }(r) \\
\text { in } 5 \text { seconds }\end{array}$ & $\begin{array}{c}\text { Probability of } \\
\text { arrival } \\
\mathbf{P}(\boldsymbol{r})^{*}\end{array}$ & $\begin{array}{c}\text { Expected } \\
\text { number of } \\
\text { arrivals }\end{array}$ & $\begin{array}{c}\text { Observed } \\
\text { number of } \\
\text { arrivals }\end{array}$ & $\begin{array}{l}\text { Theoretical } \\
\text { frequency in } \\
\text { the class }(E)\end{array}$ & $\begin{array}{c}\text { Observed } \\
\text { frequency in } \\
\text { the Class } \\
(O)\end{array}$ & $\chi^{2}=\frac{(\mathbf{O}-\mathbf{E})^{2}}{\mathbf{E}}$ \\
\hline 0 & 0.0068 & 5 & 7 & 5 & 7 & 0.976 \\
\hline 1 & 0.0341 & 24 & 36 & 24 & 36 & 5.912 \\
\hline 2 & 0.0850 & 60 & 57 & 60 & 57 & 0.149 \\
\hline 3 & 0.1412 & 100 & 98 & 100 & 98 & 0.028 \\
\hline 4 & 0.1760 & 124 & 112 & 124 & 112 & 1.203 \\
\hline 5 & 0.1754 & 124 & 121 & 124 & 121 & 0.065 \\
\hline 6 & 0.1457 & 103 & 127 & 103 & 127 & 5.649 \\
\hline 7 & 0.1038 & 73 & 71 & 73 & 71 & 0.070 \\
\hline 8 & 0.0647 & 46 & 41 & 46 & 41 & 0.475 \\
\hline 9 & 0.0358 & 25 & 30 & 25 & 30 & 0.879 \\
\hline 10 & 0.0179 & 13 & 9 & 13 & 9 & 1.031 \\
\hline 11 & 0.0081 & 6 & 8 & 6 & 8 & 0.917 \\
\hline $12 \&>$ & 0.0056 & 4 & 5 & 4 & 5 & 0.293 \\
\hline \multicolumn{5}{|c|}{$\square \chi^{2}$ Value at $5 \%$ level of Significance for 11 degrees of freedom is $=19.68$} & \multicolumn{2}{|c|}{$\chi^{2}$ Value $=17.647$} \\
\hline
\end{tabular}

\section{*As per Poisson distribution}

\section{Table 3}

Goodness-of-Fit Test for Headway Distribution

\begin{tabular}{|c|c|c|c|c|c|c|c|c|}
\hline \multirow{2}{*}{$\begin{array}{c}\begin{array}{c}\text { Class } \\
\text { Interval }\end{array} \\
0-1.4\end{array}$} & \multirow{2}{*}{\begin{tabular}{|c|}
$\begin{array}{c}\text { Lower class } \\
\text { Limit } \\
\text { 't' }\end{array}$ \\
0
\end{tabular}} & \multirow{2}{*}{$\begin{array}{c}\mathrm{e}^{-\lambda t} \\
1.000 \\
\end{array}$} & \multirow{2}{*}{$\begin{array}{c}\begin{array}{c}\text { Theoretical } \\
\text { frequency of } \\
\text { headway }>\text { Lower } \\
\text { class limit }\end{array} \\
3599 \\
\end{array}$} & \multicolumn{2}{|c|}{$\begin{array}{l}\text { Theoretical } \\
\text { frequency in } \\
\text { the Class } \\
\text { (E) }\end{array}$} & \multicolumn{2}{|c|}{$\begin{array}{c}\text { Observed } \\
\text { frequency } \\
\text { in the class } \\
(0)\end{array}$} & \multirow{2}{*}{$\frac{\chi^{2}=\frac{(\mathbf{O}-\mathbf{E})^{2}}{\mathbf{E}}}{0.090}$} \\
\hline & & & & 2842 & 2842 & 2826 & 2826 & \\
\hline $1.4-2.8$ & 1.4 & 0.210 & 757 & 598 & 598 & 600 & 600 & 0.008 \\
\hline $2.8-4.2$ & 2.8 & 0.044 & 159 & 126 & 126 & 128 & 128 & 0.041 \\
\hline $4.2-5.6$ & 4.2 & 0.009 & 33 & 26 & 26 & 32 & 32 & 1.165 \\
\hline $5.6-7.0$ & 5.6 & 0.002 & 7 & 6 & \multirow{5}{*}{7} & 6 & \multirow{5}{*}{13} & \multirow{5}{*}{5.143} \\
\hline $7-8.4$ & 7.0 & 0.000 & 1 & 1 & & 3 & & \\
\hline $8.4-9.8$ & 8.4 & 0.000 & 0 & 0 & & 2 & & \\
\hline $9.8-11.2$ & 9.8 & 0.000 & 0 & 0 & & 1 & & \\
\hline $11.2-12.6$ & 11.2 & 0.000 & 0 & 0 & & 1 & & \\
\hline \multicolumn{7}{|c|}{$\chi^{2}$ Value at $5 \%$ level of significance for 3 degrees of freedom $=7.81$} & \multicolumn{2}{|c|}{$\chi^{2}$ Value $=6.447$} \\
\hline \multicolumn{9}{|c|}{$\begin{array}{l}\text { For a negative exponential distribution, the probability } P(h \geq t)=e^{-\lambda t} \text { where, } h \text { is the } \\
\text { headway in second, } t \text { - the specified interval of time in second, and } \lambda \text {, the mean arrival rate of } \\
\text { vehicles in vehicles per second. } \\
\text { For the data given above, mean headway, } t=0.898 \mathrm{~s} . \\
\text { Hence, the mean arrival rate of vehicles, } \lambda=1 / 0.898=1.11 \text { vehicles per second. } \\
\text { Number of classes, } c=5 \text {; Hence, number of degrees of freedom }=c-2=3 \text {. } \\
\chi^{2} \text { observed }=6.447, \chi^{2} \text { theoretical }=7.81 \text { (at } 5 \% \text { significance level and } 3 \text { degrees of freedom). } \\
\text { Since the } \chi^{2} \text { observed, is lesser than the } \chi^{2} \text { theoretical there is no significant difference between the } \\
\text { observed and theoretical (Exponential) headway distributions. }\end{array}$} \\
\hline
\end{tabular}




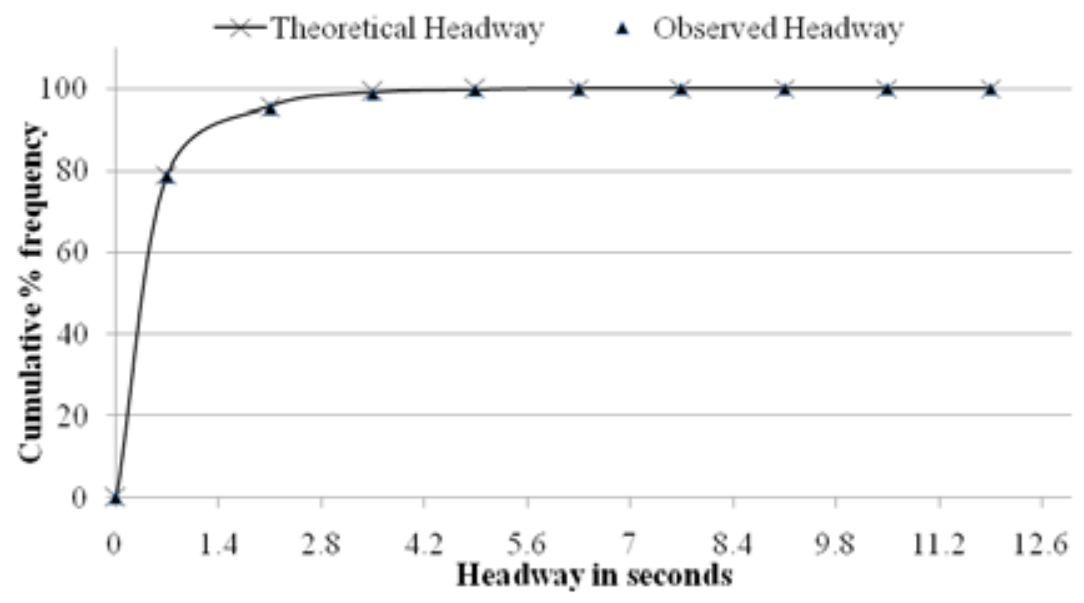

Fig. 4.

Observed and Theoretical Headways

\subsection{Model Validation}

Validation is the determination that a model is an accurate representation of the real system. For validating the simulation model, the traffic flow through a length of $1400 \mathrm{~m}$ of roadway, with the same geometric features as that of the study stretch was simulated. The observed roadway condition, traffic volume and composition were given as input to the simulation process. The inter arrival time (headway) of vehicles was found to fit into negative exponential distribuion. For the purpose of model validation, it was decided to consider the derived traffic flow characteristics, at the micro level, so that the validation is satisfactory. Accordingly, the field observed and simulated mean speeds of each of the categories of vehicles were compared to check for the validity of the model. For this purpose, simulation runs were made with three random number seeds and the average of the three values was taken as the final result. A comparison of the observed and simulated average speeds of the different types of vehicles is shown in Fig. 5. It can be seen that the simulated speed values significantly replicate the field observed speeds for all vehicle types. The simulated speeds were also statistically compared with observed speed values. For this purpose, a paired $t$-test of null hypothesis of no- mean-difference was performed to check for the match between simulated and observed average speeds of vehicles. The calculated value of $t\left(t_{0}\right)$ is 1.968 against the critical value (from ' $t$ ' table) of 2.57. It was found that the observed and simulated average speeds matched at 5\% level of significance (95\% confidence limit).

\section{Model Application}

The PCU has been defined by Transport and Road Research Laboratory (TRRL), London, UK in 1965 as follows: "on any particular section of road under particular traffic conditions, if the addition of one vehicle of a particular type per hour will reduce the average speed of the remaining vehicles by the same amount as the addition of, say $x$ cars of average size per hour, .... then, one 


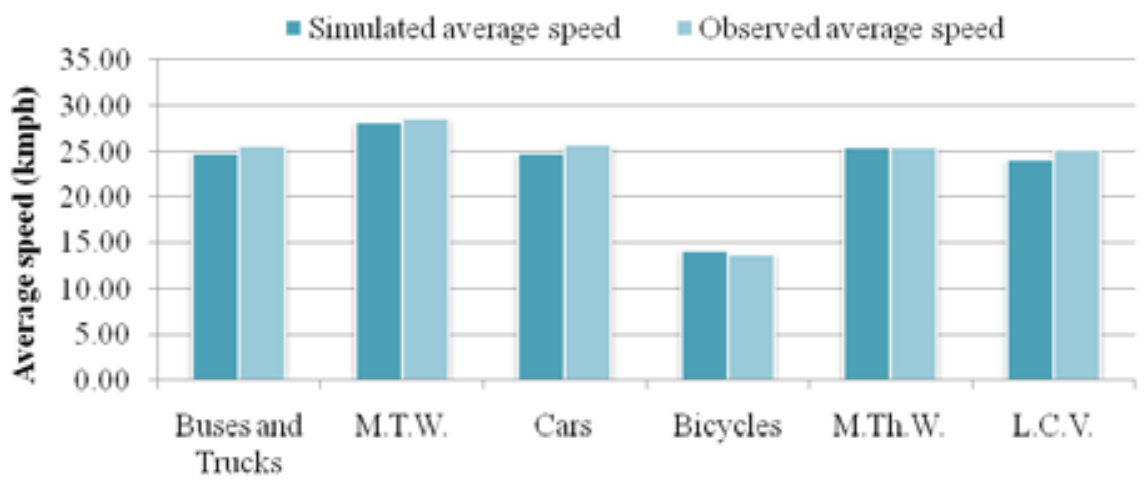

Vehicle type

L.C.V. - Light Commercial Vehicles, M.Th.W. - Motorized Three-Wheelers, M.T.W. - Motorized Two-Wheelers

\section{Fig. 5.}

\section{Simulated and Observed Speeds}

vehicle of this type is equivalent to $x$ PCU." This definition has been taken as the basis for derivation of equivalency values, for the different types of vehicles, in this study.

\subsection{Estimation of Equivalency Values of Vehicles in Cars-Only Traffic Stream}

One of the prime objectives of this study is to estimate the equivalency values of different vehicle types while moving in cars-only traffic stream, which will provide an estimate of the amount of impedance caused by a vehicle type to the flow of the traffic stream comprising cars and the subject vehicles only. This relative influence is quantified and named as Basic Passenger Car Unit (BPCU). These equivalency values will serve as the base for comparison of the impedance caused by vehicles in heterogeneous traffic.

The width of road space available for movement of traffic in one direction was fixed as $7.5 \mathrm{~m}$ (equivalent to the width of road space for one direction of movement on a four-lane divided urban road). The total length of simulation road stretch considered for the experiments is $1400 \mathrm{~m}$, with $200 \mathrm{~m}$ sections at the entry and exit of the stretch excluded from output data collection. The $200 \mathrm{~m}$ long stretches at the entry and the exit respectively were used as warm-up and tail-end stabilisation zones respectively. The central $1000 \mathrm{~m}$ long stretch was considered as the observation zone and the various traffic flow parameters were recorded while a vehicle is traversing through this zone.

The validated model was first used to simulate homogeneous traffic ( $100 \%$ passenger cars) flow in one direction, on a level four-lane divided urban road, over a wide range of traffic volume (flow) to develop the fundamental speed-flow relationship. The simulation runs were repeated using three different random number streams to ensure consistency of the results. During the simulation runs, the traffic volume on the study stretch was varied from a very low volume level to capacity-flow level. Through the simulation runs, the simulated output values of volumes and speeds were recorded. It was noted that when simulation 
runs were made with successive increments in traffic volume (input), there were increase in the exit volume at the end of the simulation stretch. When the simulated volume reached the capacity level, however, the increments in the input traffic volumes did not result in the same amounts of increase in the exit volume, and resulted in a decrease in the rate of traffic flow. A few successive decreases in the exit volume, in spite of increase in the input, indicate that the roadway has reached its capacity. The speed-flow relationship obtained, through the simulation process, is depicted graphically in Fig. 6. Using the speedflow curve, the capacity value of $7.5 \mathrm{~m}$ wide road space under the purely homogeneous (cars-only) traffic condition, with traffic flow in one direction, was then obtained as, about 3400 passenger cars per hour, as shown in Fig. 6.

The variation of BPCU values at different compositions for all different categories of vehicles was studied at various volumecapacity $(\mathrm{V} / \mathrm{C})$ ratios starting from very low volume to capacity level. The range of the set of compositions for the different categories of vehicles was fixed based on the field observed values. The simulation procedure followed for determination of BPCU value is as follows. The cars-only traffic was simulated for various volume-capacity $(\mathrm{V} / \mathrm{C})$ ratios of $0.1,0.3,0.5$, $0.7,0.9$ and 1 . The simulated output values of volumes and the corresponding speeds of cars were recorded. To the cars-only traffic, the required number of subject vehicle was introduced and then, through simulation runs, the simulated output values of volumes and speeds (car speeds and subject vehicle speeds) were recorded. The volume of the mixed traffic was varied (through iterative process) such that, the average speed of cars, remained the same, before and after the replacement of cars with subject vehicles. Then, the number of cars removed divided by the number of the subject-vehicle type

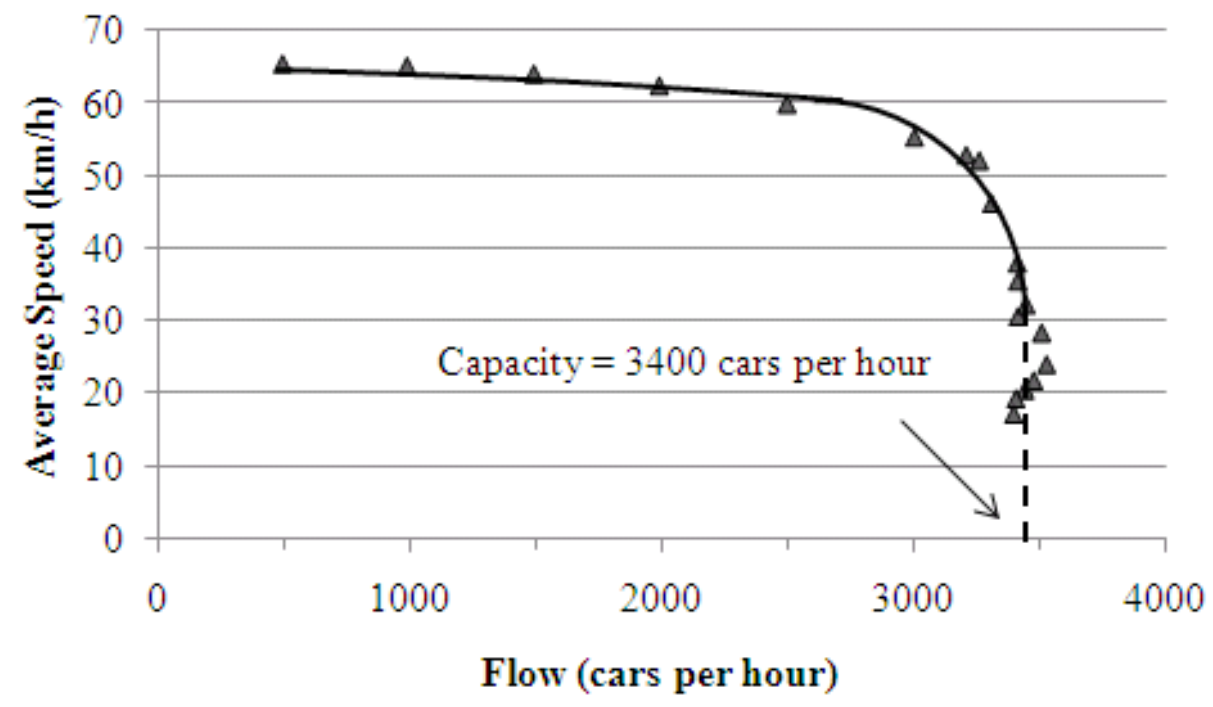

Fig. 6.

Speed-Flow Relationship on 7.5 m Wide Road under Homogeneous Traffic Condition 
introduced as replacement for the removed cars, will give the BPCU value of the vehicle type. To account for the variation due to randomness, the simulation runs were made with three random number seeds and the average of the three values was taken as the final value. The variation of BPCU values for the different motorized vehicle categories over traffic volume and traffic composition, on $7.5 \mathrm{~m}$ wide road space, are shown in Figs. 7 through 11 .

In Chennai city, out of the total width of $7.5 \mathrm{~m}$ of road space available for vehicle movement, a $1.5 \mathrm{~m}$ wide road space, adjacent to the curb, is reserved for bicycles by making paint marking on the pavement surface. However, during data collection from the study stretch it was found that motorized vehicles made use of the cycle track in cases of absence of bicycles on the track. This scenario is seen in all the urban roads in India where heterogeneous traffic exists. Hence, as per the placement logic of the simulation program, non-motorised vehicles such as bicycles are confined to the left most $1.5 \mathrm{~m}$ width of the road only, whereas motorised vehicles are assumed to occupy any lateral position, depending on the availability of longitudinal and transverse gaps, including the road space reserved for bicycles in the absence of bicycles. The change in the speed of bicycles (slow moving vehicles) is very less with increase in volume, as compared to the reference vehicle, (cars) as there is exclusive road space available for bicycles. Accordingly, due to the higher speed difference between motorised and non-motorised (bicycles) traffic, behaviour of motorised traffic in the presence of bicycles is totally different. Hence, a different method has to be followed to quantify the impedance offered by the bicycles in homogenous traffic. The bicycle compositions of $2 \%, 4 \%, 6 \%, 8 \%$ and $10 \%$ along with cars were considered for study. At first, capacity at each of these compositions was found out from the corresponding speed-

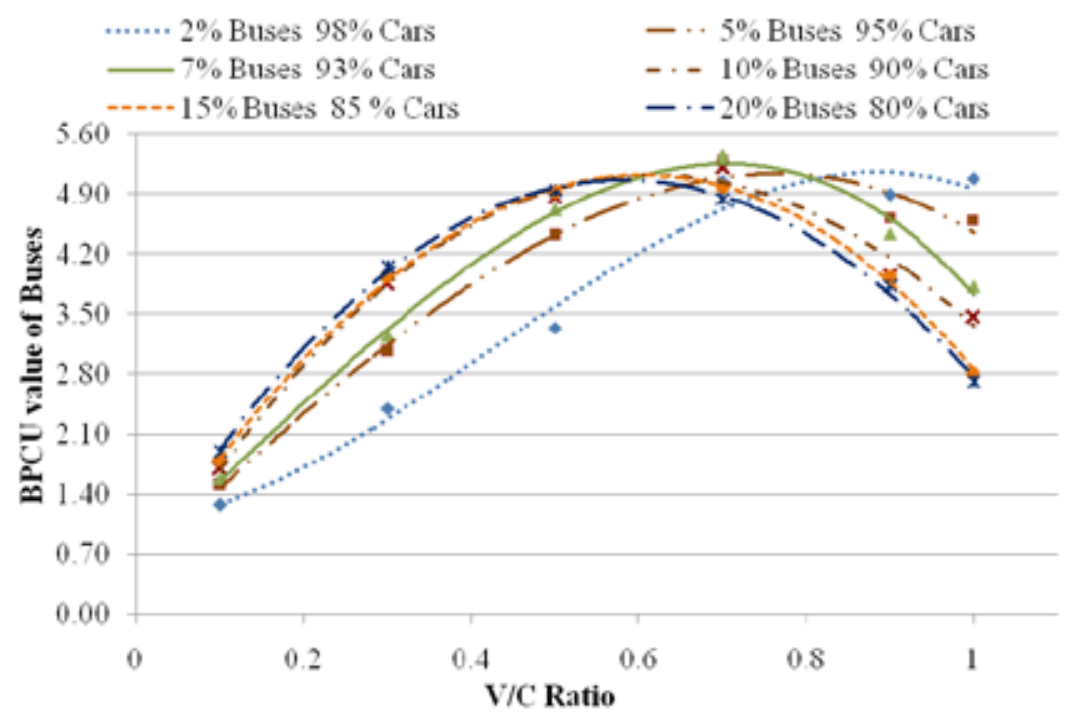

Fig. 7.

Variation of BPCU Value of Buses 


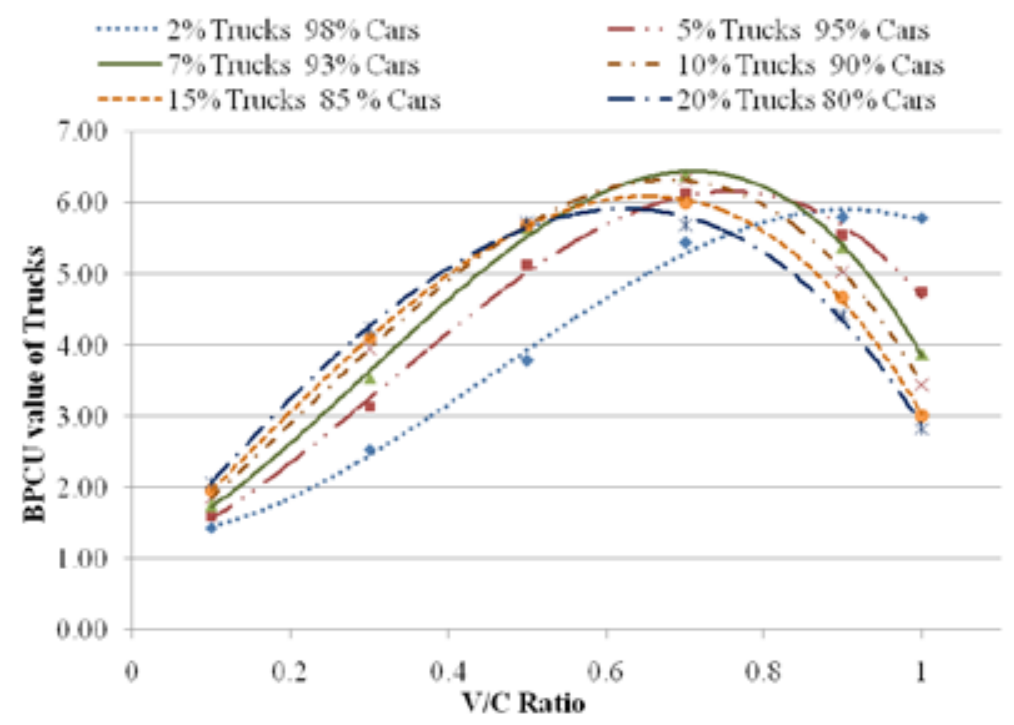

Fig. 8.

Variation of BPCU Value of Trucks

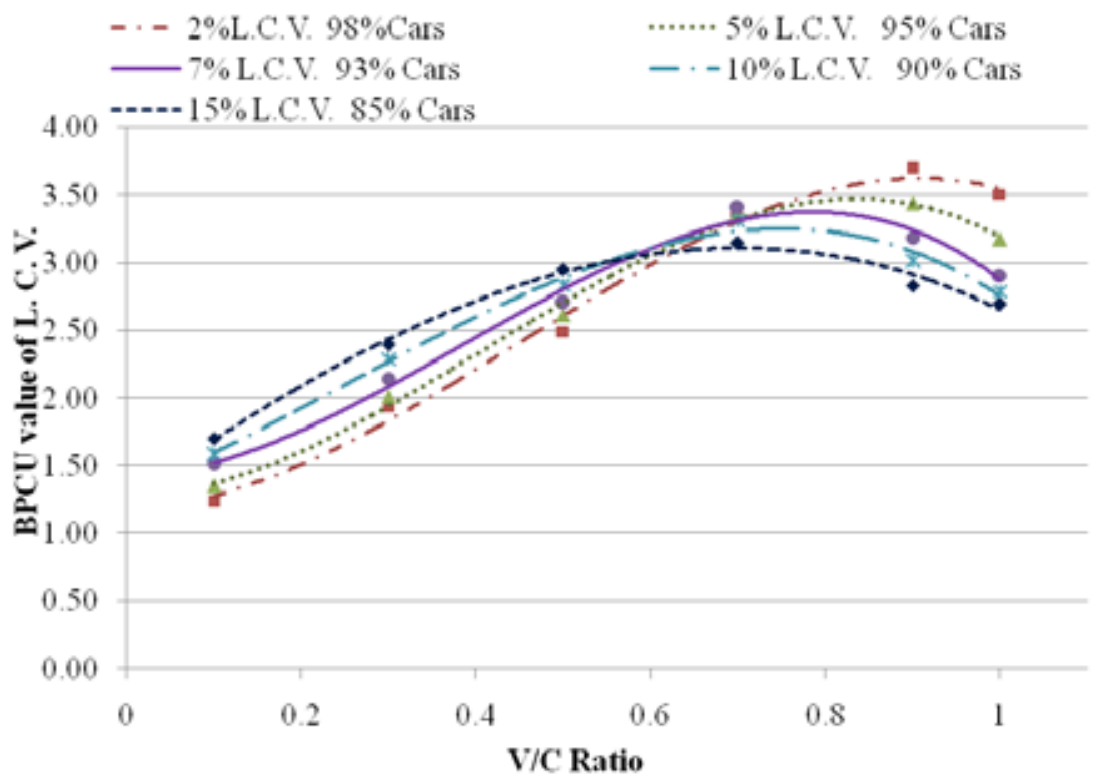

Fig. 9.

Variation of BPCU Value of Light Commercial Vehicles 


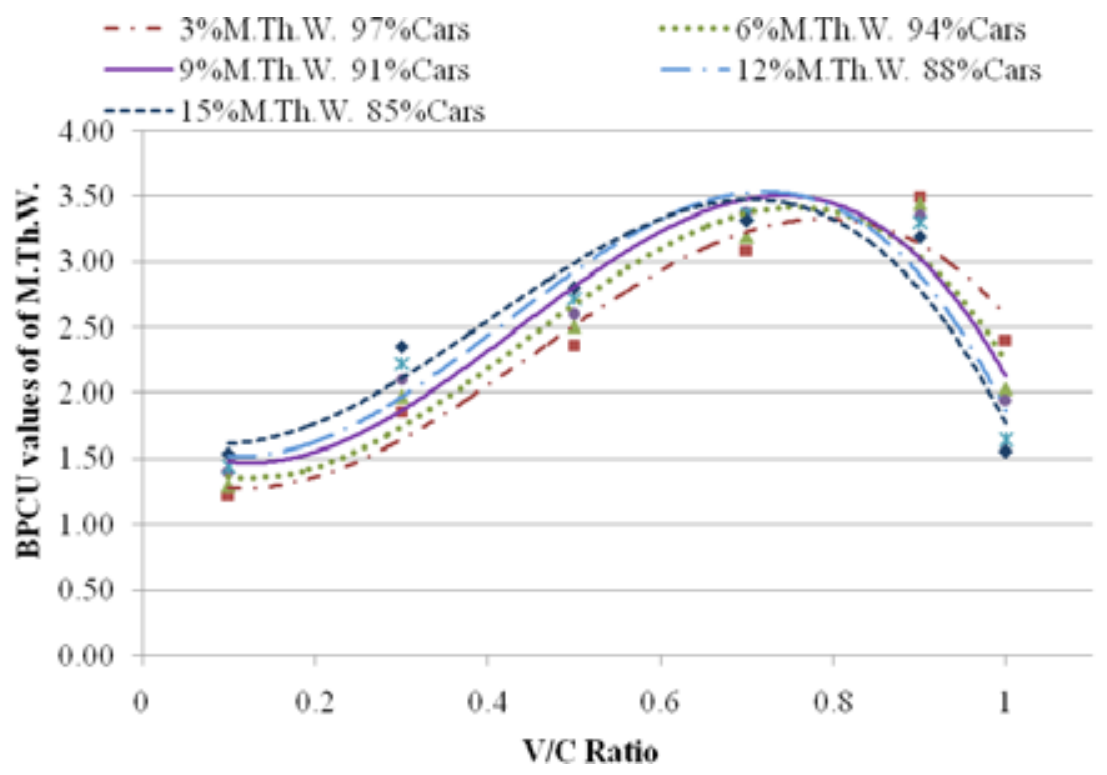

Fig. 10.

Variation of BPCU Value Motorised Three-Wheelers

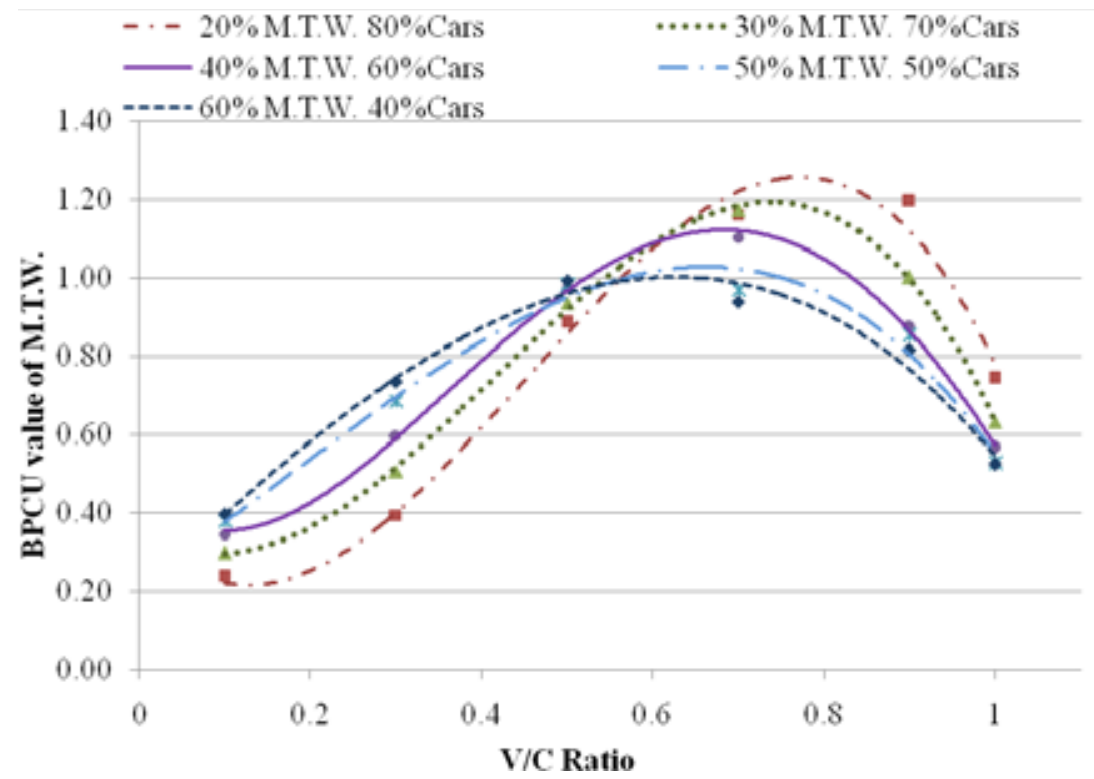

Fig. 11.

Variation of BPCU Value of Motorised Two-Wheelers 
flow curves. The traffic was simulated for each of these compositions for various volumecapacity $(\mathrm{V} / \mathrm{C})$ ratios of $0.1,0.3,0.5,0.7$, 0.9 and 1 . The simulated output values of car volumes, car speeds, bicycle speeds and bicycle volumes were recorded. For calculating PCU value corresponding to a $\mathrm{V} / \mathrm{C}$ ratio, in each case, a certain percentage $(1 \%-4 \%)$ of cars were replaced by the bicycles (for which the $\mathrm{BPCU}$ value is to be estimated) in the mixed traffic stream, such that the average speed of cars obtained by simulation, before and after replacement, remained the same. Then, for each flow level, the number of cars removed divided by the number of bicycles introduced will give the BPCU value of bicycles. The logic behind the above approach is that, as stated in the definition of PCU, the introduced bicycles create more or less the same effect on the traffic stream that is equivalent to that of the cars removed from the stream. To account for the variation due to randomness, the simulation runs were made with three random number seeds and the average of the three values was taken as the final value. The variation of BPCU values of bicycles over traffic volume and composition on $7.5 \mathrm{~m}$ wide road space is depicted in Fig. 12.

\subsection{Estimation of PCU Values of Vehicles under Heterogeneous Traffic Conditions}

The PCU values for the different types of vehicles on four lane divided urban road, at various volume levels and traffic composition, were estimated by taking the stream speed (stream with motorized vehicles only) as the measure of performance. The main objective is to study the effect of composition of one category of vehicles at a time on the PCU values. To accomplish this, the change in composition of one particular category of vehicles was entirely compensated by changing the composition of cars, keeping the composition of other categories of vehicles constant. A base traffic composition,

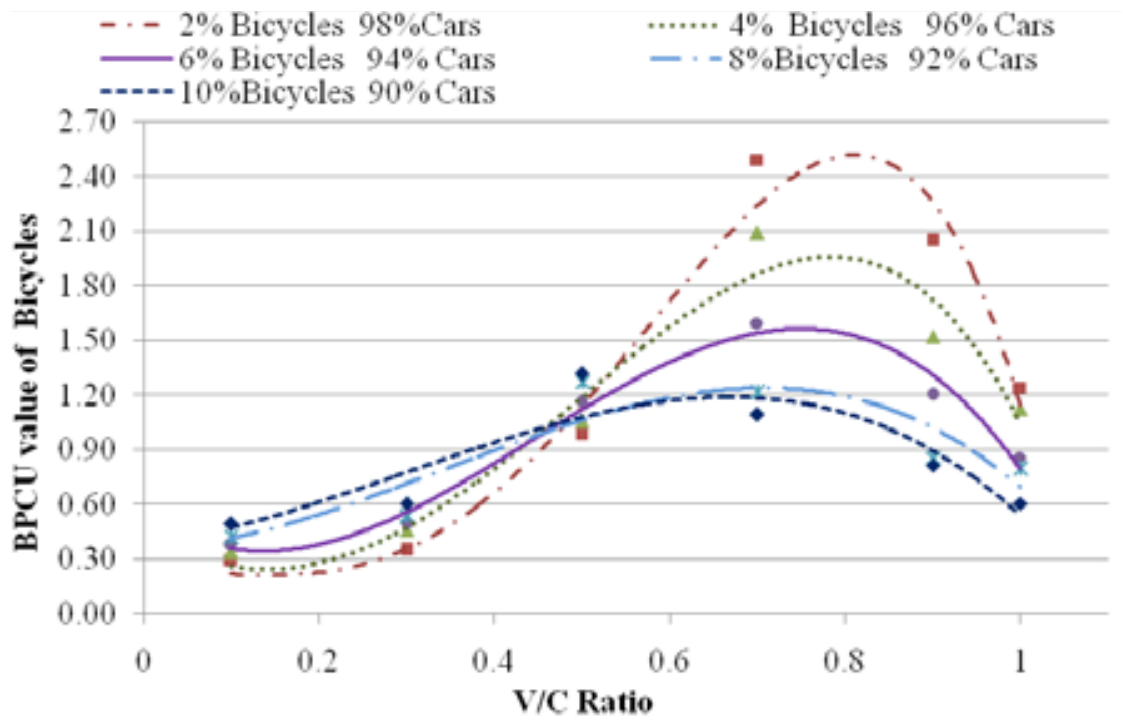

Fig. 12.

Variation of BPCU Value of Bicycles 
as depicted in Fig. 13 was fixed for the study on the basis of field observed traffic compositions.

The speed-flow relationship, which forms the basis for estimation of PCU values of vehicles, was developed, for each of the compositions considered in this study, for traffic flow on $7.5 \mathrm{~m}$ wide urban road space. The method adopted for estimation of PCU values involves the following steps: (i) Capacity at each of the compositions was found out from the corresponding speed-flow curves. (ii) For the analysis purpose, six traffic-volume levels, corresponding to volume-to-capacity (V/C) ratios of $0.1,0.3,0.5,0.7,0.9$ and 1.0 , were considered. (iii) The simulated output values of volumes and speeds of all vehicle categories were recorded, and the average speed of the traffic stream comprising all the motorized vehicles were calculated. (iv) For calculating $\mathrm{PCU}$ value corresponding to a $\mathrm{V} / \mathrm{C}$ ratio, in each case, a certain percentage $(1 \%-3 \%)$ of cars were replaced by the subject vehicle type (for which the PCU value is to be estimated) in the mixed traffic stream, such that the average stream speed obtained by simulation, before and after replacement, remained the same. (v) Then, for each flow level, the number of cars removed divided by the number of subjectvehicle type introduced will give the PCU value of that vehicle type. The logic behind the above approach is that, as stated in the definition of PCU, the introduced subject vehicle type creates more or less the same effect on the traffic stream that is equivalent to that of the cars removed from the stream. The PCU values of the subject-vehicle were determined, following the said procedure, for $7.5 \mathrm{~m}$ wide road space, considering a set of different traffic compositions at various pre fixed $\mathrm{V} / \mathrm{C}$ ratio levels of the heterogeneous traffic. To account for the variation due to randomness, the simulation runs were made with three random number seeds and the average of the three values was taken as the final value. The variation of PCU values of for the different vehicle categories over traffic volume and traffic composition, on $7.5 \mathrm{~m}$ wide road space, has been depicted in Figs. 14 through 18.

\subsection{Trend of Variation of PCU Value}

It can be seen that both under homogeneous and heterogeneous traffic conditions, the change in the magnitude of impedance to vehicular traffic flow, in terms of PCU value shows an increasing trend at the lower volume levels. The increasing trend continues up to certain volume level beyond which the PCU value exhibits a decreasing trend. Also, it is

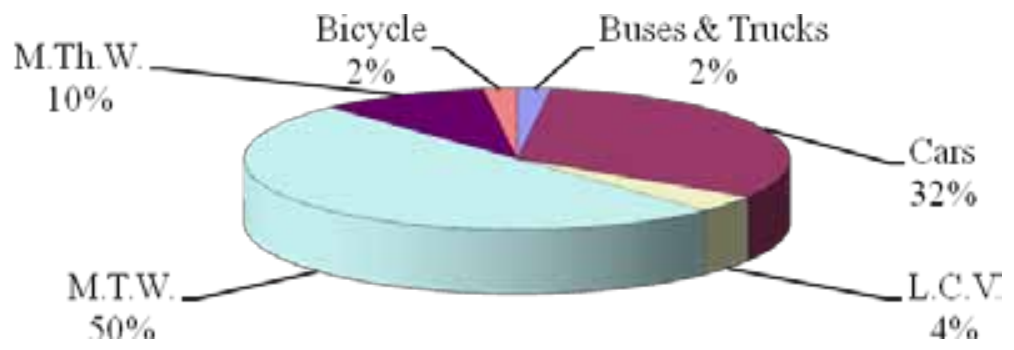

L.C.V. - Light Commercial Vehicles, M.Th.W. - Motorized Three-Wheelers, M.T.W. - Motorized Two-Wheelers

Fig. 13.

Base Traffic Composition 


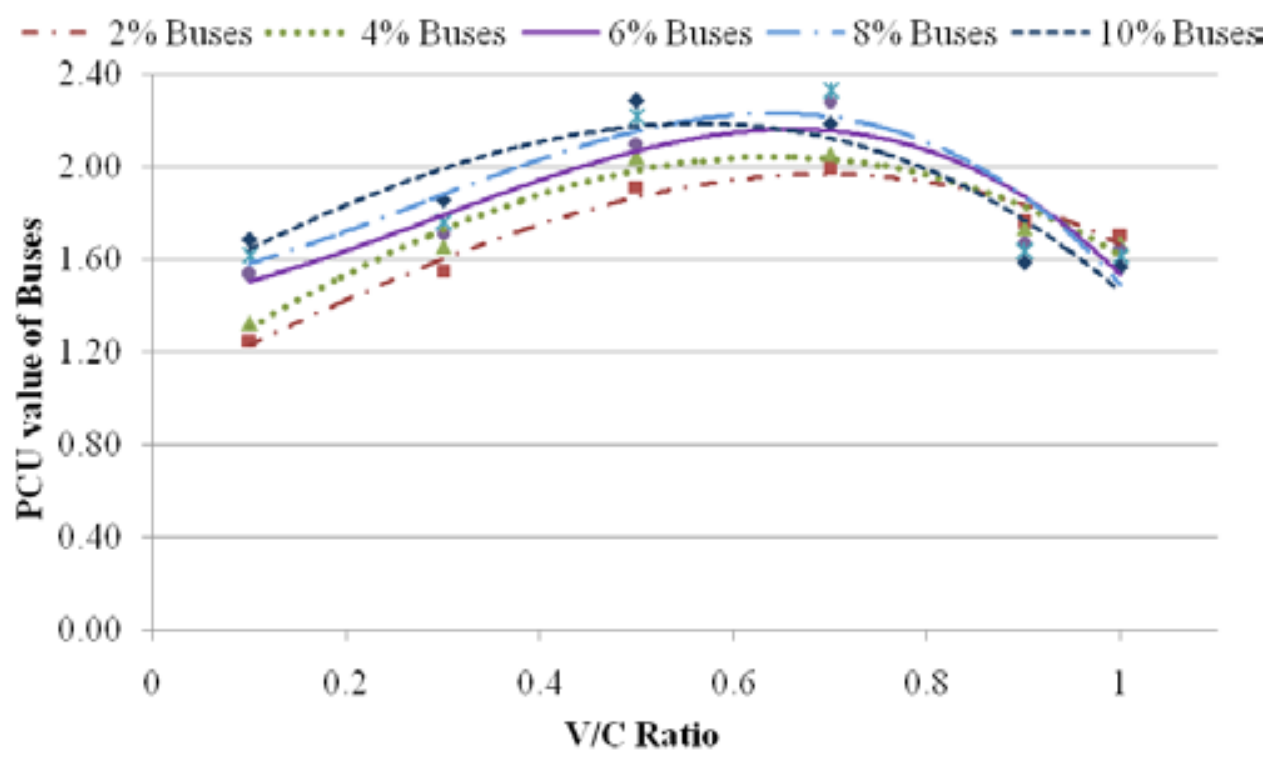

Fig. 14.

Variation of PCU Value of Buses

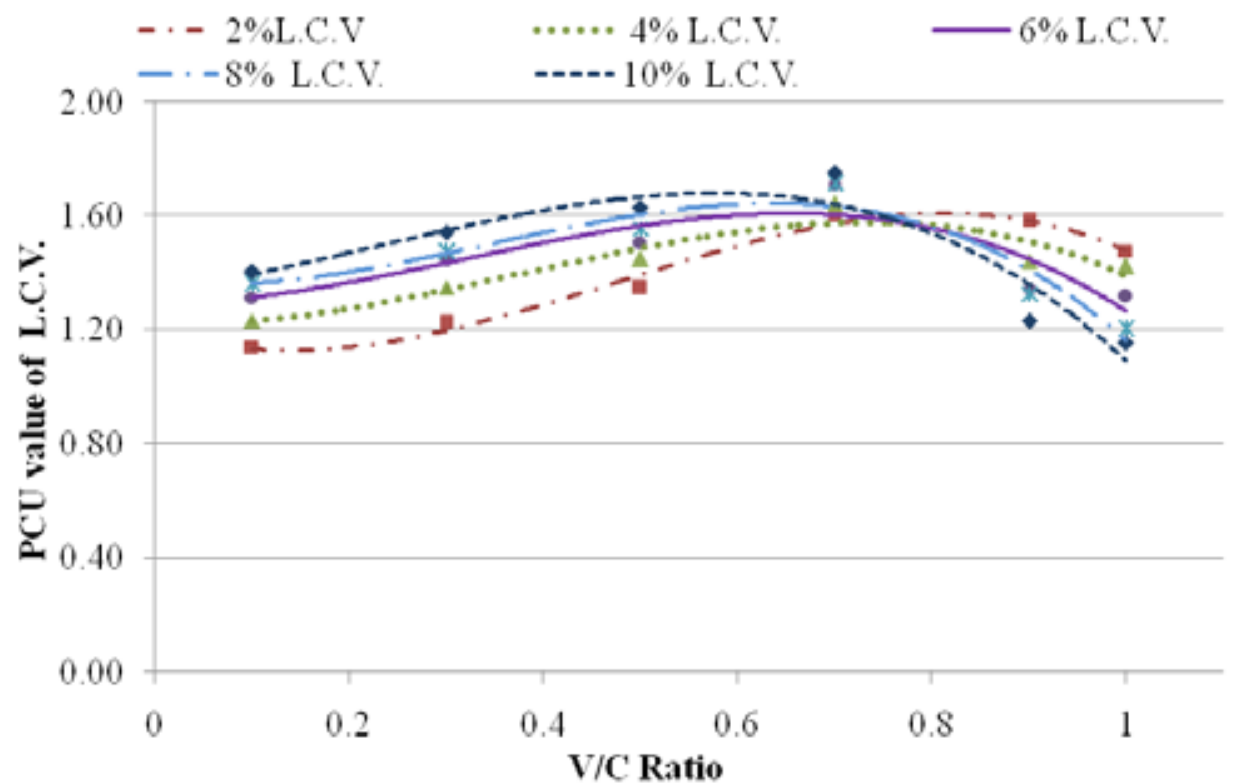

Fig. 15.

Variation of PCU Value of Light Commercial Vehicles 


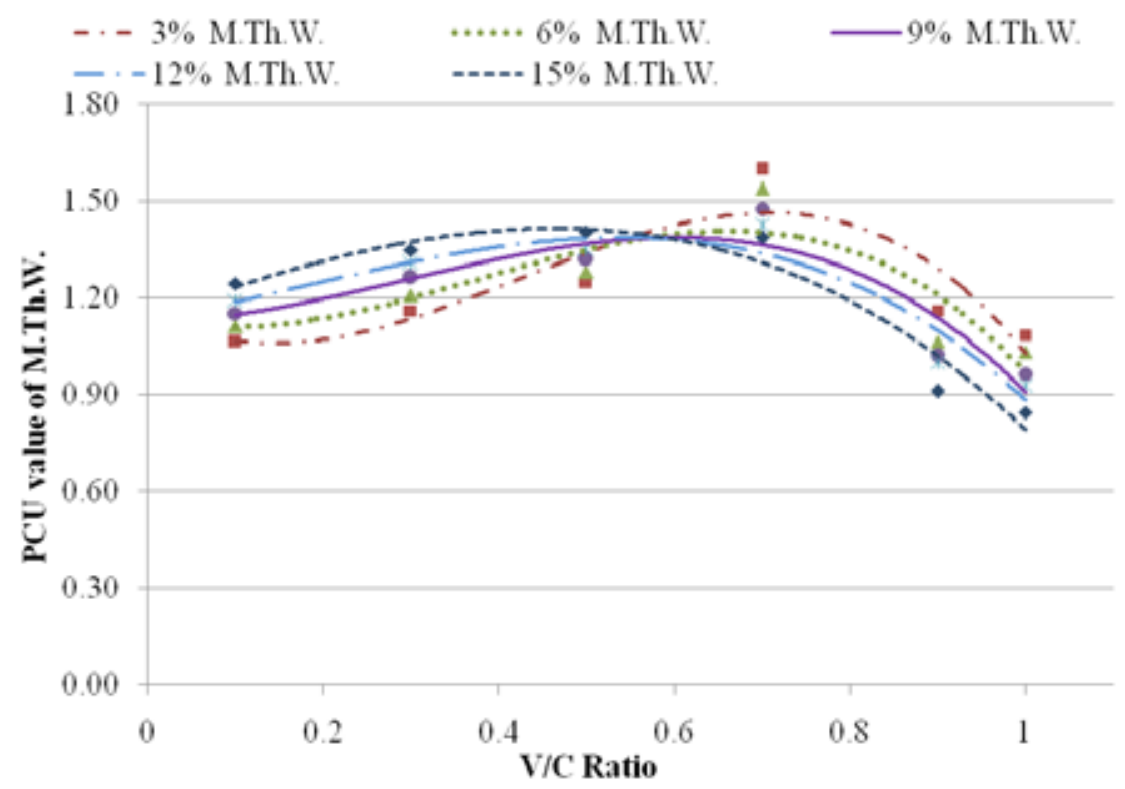

Fig. 16.

Variation of PCU Value of Motorised Three-Wheelers

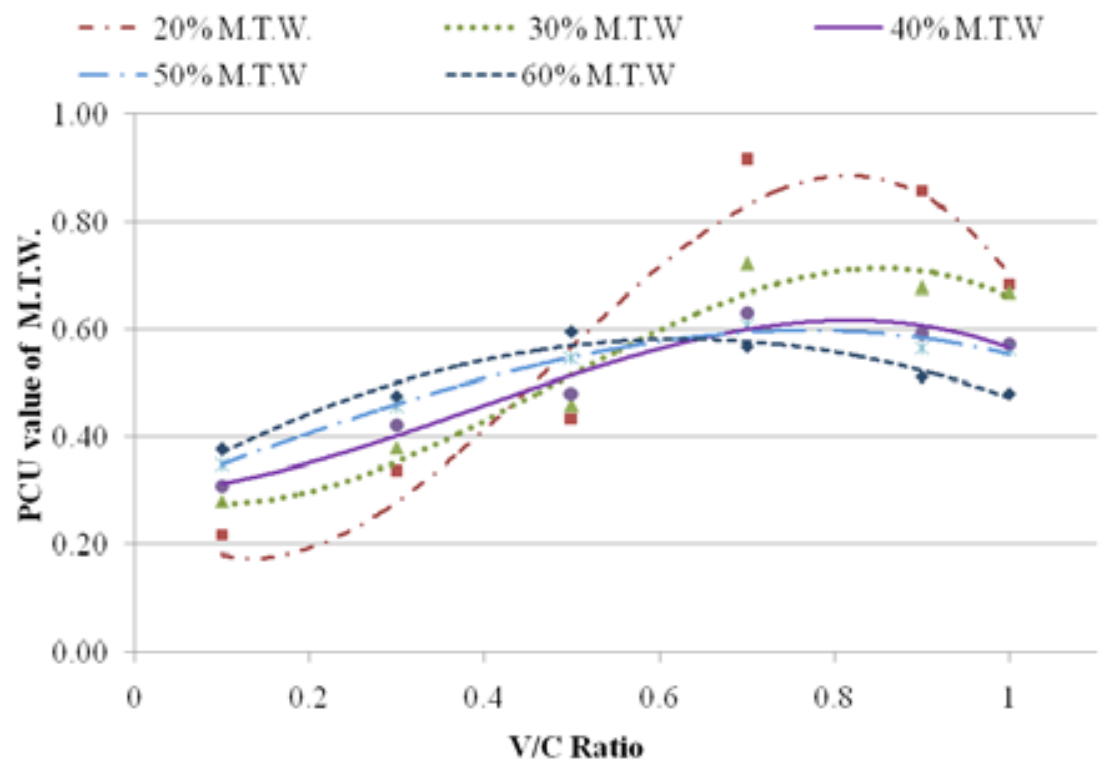

Fig. 17.

Variation of PCU Value of Motorised Two-Wheelers 


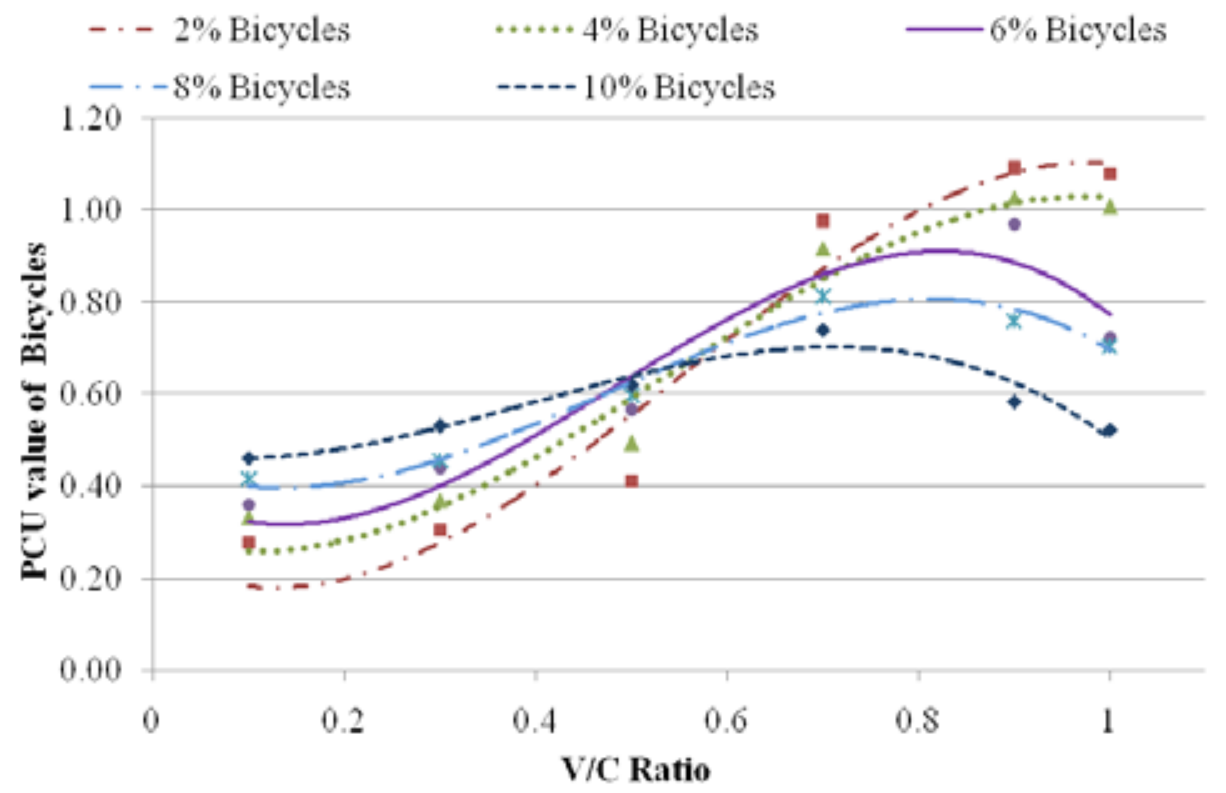

Fig. 18.

Variation of PCU Value of Bicycles

found that the range of variation of PCU value for any given subject vehicle is wide when the composition of that vehicle is less and this decreases with increase in the composition. The root cause for the trend of variation of $\mathrm{PCU}$ value over volume (V/C ratio) and composition, is the relative changes, caused by the overall traffic environment, in the speeds of the reference vehicle (car) and the subject vehicle (for which PCU value is estimated), at various traffic volume levels (Arasan and Arkatkar, 2010). To check the said earlier finding, the variation in the change in speed difference between the cars and the subject vehicle category, in the case of heterogeneous traffic was estimated. For this purpose the difference in percentage speed change, in respect of cars and the subject vehicle category was calculated as the difference between percentage change in speed of cars and the percentage change in speed of subject- vehicle category, for the successive $\mathrm{V} / \mathrm{C}$ ratios. Then plots depicting the variation of speed difference over traffic volume ( $\mathrm{V} / \mathrm{C}$ ratio), for a set of chosen traffic compositions were made, as example for heterogeneous traffic conditions (Figs. 19 through 23). From the plots, it can be noted that the trend lines showing the variation of speed difference over $\mathrm{V} / \mathrm{C}$ ratio and composition exhibit the same pattern as to that of PCU value of subject vehicles. Thus, it can be understood that the change in PCU value over traffic volume and composition is directly related to the change in speed difference between the reference vehicle (car) and the subject vehicle.

\subsection{Effect of Heterogeneity on PCU Values}

A careful comparison of the variation of PCU value under cars-only condition (Figs. 7-12) 


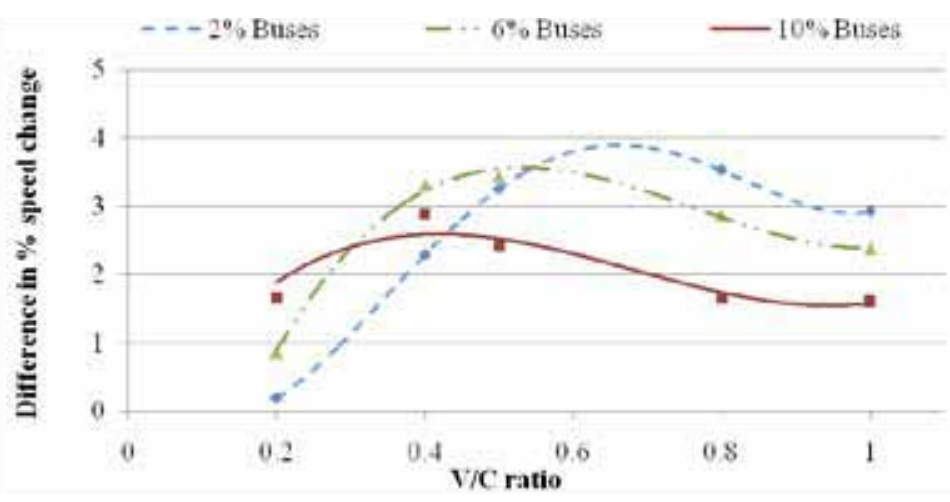

Fig. 19.

Variation in Change in Speed Difference between Cars and Buses

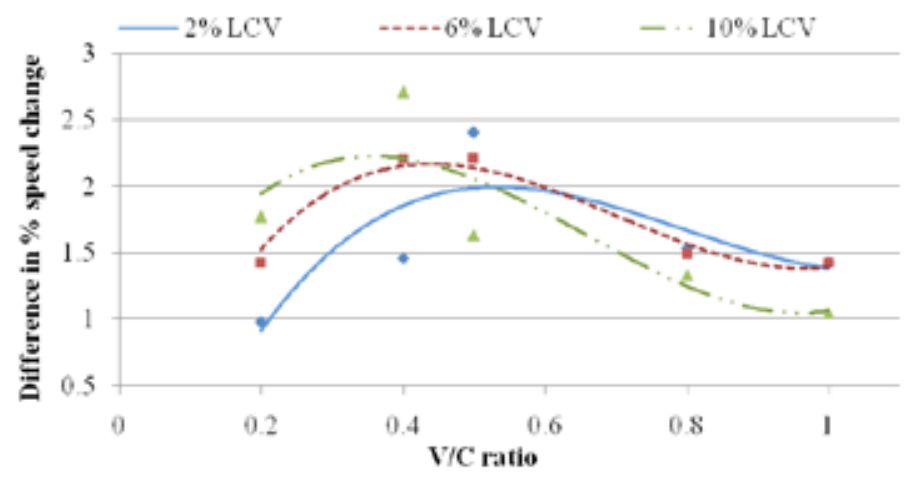

Fig. 20.

Variation in Change in Speed Difference between Cars and Light Commercial Vehicles

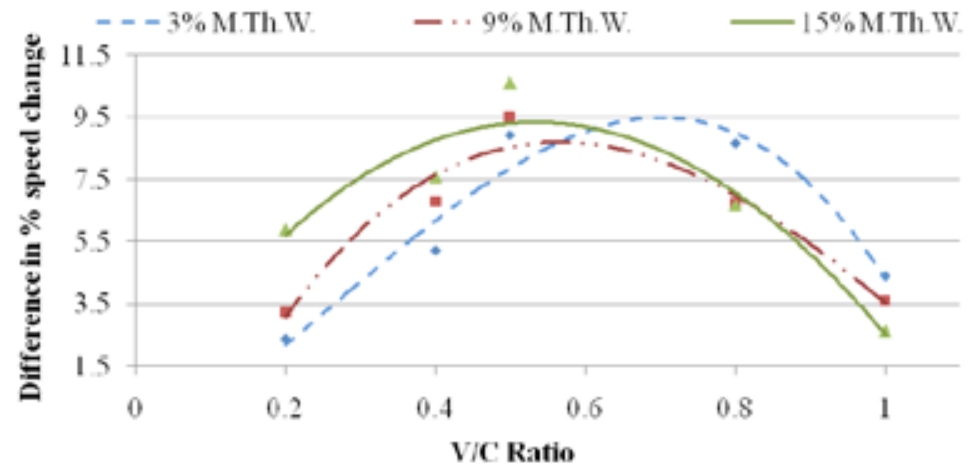

Fig. 21.

Variation in Change in Speed Difference between Cars and Motorised Three-Wheelers 


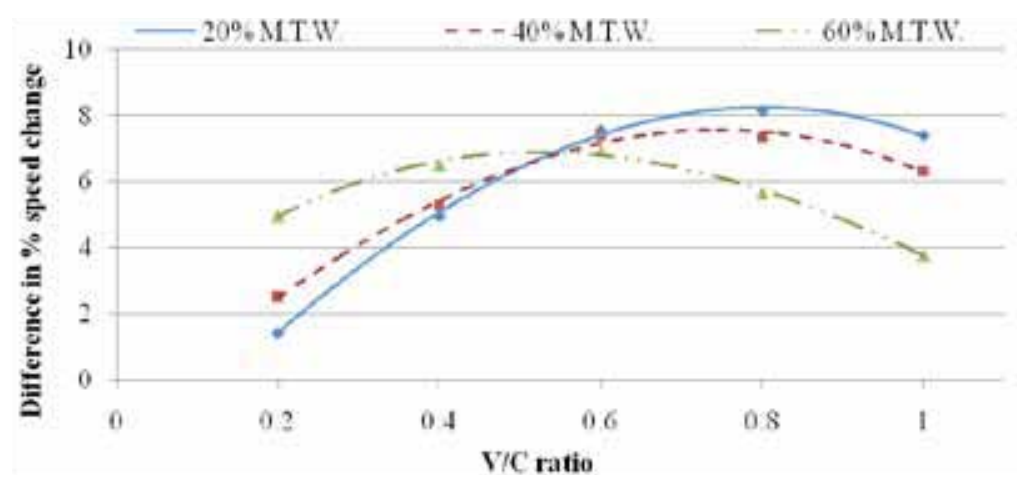

Fig. 22.

Variation in Change in Speed Difference between Cars and Motorised Two-Wheelers

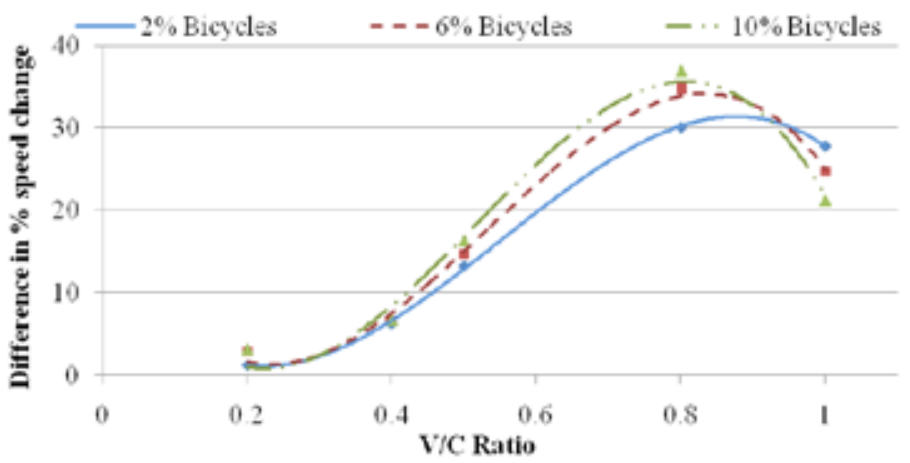

Fig. 23.

Variation in Change in Speed Difference between Cars and Bicycles

and heterogeneous traffic condition (Figs. 14-18) reveals that the PCU value of a vehicle type in homogeneous (cars-only) traffic is higher in magnitude compared to its value in heterogeneous traffic. The details are given in Table 4. It can be seen from Table 4 that, the magnitude of vehicular impedance to traffic flow measured in terms of BPCU, under cars-only traffic condition is significantly higher for the corresponding vehicle types when compared to their values under heterogeneous traffic condition. The higher PCU values under cars-only traffic condition may be attributed to higher relative speed difference between the car speed and the subject vehicle speed in cars-only traffic, than, the relative speed difference between the car speed and subject vehicle speed under heterogeneous traffic condition as shown in Table 5. It may be noted that though the overall size of the motorized two-wheeler is very much smaller than the passenger car, the significantly higher relative speed difference between cars and motorized two-wheelers at certain volume levels (V/C ratio 0.7 to 0.9 ) gives a relatively higher PCU value (more than unity) for motorized two-wheelers with cars-only traffic. 
Table 4

Comparison of BPCU Values and PCU Values on $7.5 \mathrm{~m}$ Wide Road

\begin{tabular}{|l|l|l|l|l|l|l|}
\hline V/C Ratio* & BPCU Value & PCU Value & BPCU Value & PCU Value & BPCU Value & PCU Value \\
\hline
\end{tabular}

Subject Vehicle: Bus

\begin{tabular}{|l|l|l|l|l|l|r|}
\hline & \multicolumn{9}{|c|}{ Vehicle Composition } \\
\cline { 2 - 7 } 0.1 & \multicolumn{2}{|c|}{$2 \%$} & \multicolumn{2}{c|}{$5 \%$} & \multicolumn{2}{c|}{$10 \%$} \\
\cline { 2 - 7 } & 1.30 & 1.23 & 1.48 & 1.41 & 1.69 & 1.64 \\
\hline 0.3 & 2.30 & 1.60 & 3.11 & 1.76 & 3.85 & 1.99 \\
\hline 0.5 & 3.60 & 1.87 & 4.43 & 2.03 & 4.96 & 2.17 \\
\hline 0.7 & 4.73 & 1.97 & 5.08 & 2.10 & 5.04 & 2.12 \\
\hline 0.9 & 5.16 & 1.84 & 4.91 & 1.86 & 4.14 & 1.77 \\
\hline 1.0 & 4.98 & 1.67 & 4.46 & 1.58 & 3.38 & 1.46 \\
\hline
\end{tabular}

Subject Vehicle: L.C.V.

\begin{tabular}{|c|c|c|c|c|c|c|}
\hline \multirow[b]{3}{*}{0.1} & \multicolumn{6}{|c|}{ Vehicle Composition } \\
\hline & \multicolumn{2}{|c|}{$2 \%$} & \multicolumn{2}{|c|}{$5 \%$} & \multicolumn{2}{|c|}{$10 \%$} \\
\hline & 1.28 & 1.13 & 1.37 & 1.27 & 1.59 & 1.39 \\
\hline 0.3 & 1.83 & 1.20 & 1.94 & 1.39 & 2.27 & 1.55 \\
\hline 0.5 & 2.61 & 1.39 & 2.70 & 1.53 & 2.89 & 1.67 \\
\hline 0.7 & 3.31 & 1.57 & 3.31 & 1.60 & 3.24 & 1.64 \\
\hline 0.9 & 3.63 & 1.58 & 3.42 & 1.48 & 3.08 & 1.36 \\
\hline 1.0 & 3.55 & 1.48 & 3.18 & 1.33 & 2.75 & 1.09 \\
\hline
\end{tabular}

Subject Vehicle: M.Th.W.

\begin{tabular}{|c|c|c|c|c|c|c|}
\hline \multirow[b]{3}{*}{0.1} & \multicolumn{6}{|c|}{ Vehicle Composition } \\
\hline & \multicolumn{2}{|c|}{$3 \%$} & \multicolumn{2}{|c|}{$9 \%$} & \multicolumn{2}{|c|}{$15 \%$} \\
\hline & 1.28 & 1.06 & 1.47 & 1.15 & 1.62 & 1.23 \\
\hline 0.3 & 1.65 & 1.14 & 1.86 & 1.26 & 2.11 & 1.37 \\
\hline 0.5 & 2.52 & 1.34 & 2.80 & 1.37 & 2.99 & 1.41 \\
\hline 0.7 & 3.24 & 1.46 & 3.47 & 1.36 & 3.48 & 1.31 \\
\hline 0.9 & 3.15 & 1.29 & 3.02 & 1.14 & 2.78 & 1.02 \\
\hline 1.0 & 2.60 & 1.02 & 2.13 & 0.90 & 1.77 & 0.79 \\
\hline
\end{tabular}

Subject Vehicle: M.T.W.

\begin{tabular}{|c|c|c|c|c|c|c|}
\hline \multirow[b]{3}{*}{0.1} & \multicolumn{6}{|c|}{ Vehicle Composition } \\
\hline & \multicolumn{2}{|c|}{$20 \%$} & \multicolumn{2}{|c|}{$40 \%$} & \multicolumn{2}{|c|}{$60 \%$} \\
\hline & 0.22 & 0.18 & 0.35 & 0.31 & 0.40 & 0.37 \\
\hline 0.3 & 0.40 & 0.27 & 0.59 & 0.40 & 0.74 & 0.50 \\
\hline 0.5 & 0.86 & 0.57 & 0.97 & 0.52 & 0.96 & 0.57 \\
\hline 0.7 & 1.22 & 0.83 & 1.12 & 0.60 & 0.99 & 0.57 \\
\hline 0.9 & 1.12 & 0.85 & 0.87 & 0.61 & 0.77 & 0.52 \\
\hline 1.0 & 0.78 & 0.70 & 0.58 & 0.57 & 0.55 & 0.47 \\
\hline
\end{tabular}

Subject Vehicle: Bicycle

\begin{tabular}{|l|l|l|l|l|l|l|}
\hline \multirow{2}{*}{0.1} & \multicolumn{9}{|c|}{ Vehicle Composition } \\
\cline { 2 - 7 } & \multicolumn{2}{|c|}{$2 \%$} & \multicolumn{2}{|c|}{$6 \%$} & \multicolumn{2}{c|}{$10 \%$} \\
\cline { 2 - 7 } & 0.21 & 0.18 & 0.35 & 0.32 & 0.47 & 0.46 \\
\hline 0.3 & 0.35 & 0.28 & 0.55 & 0.40 & 0.77 & 0.53 \\
\hline 0.5 & 1.12 & 0.55 & 1.12 & 0.64 & 1.07 & 0.64 \\
\hline 0.7 & 2.24 & 0.87 & 1.54 & 0.86 & 1.18 & 0.70 \\
\hline 0.9 & 2.26 & 1.08 & 1.31 & 0.89 & 0.89 & 0.62 \\
\hline 1.0 & 1.15 & 1.10 & 0.80 & 0.77 & 0.54 & 0.50 \\
\hline
\end{tabular}

${ }^{*}$ Volume-to-Capacity (V/C) Ratio 


\section{Table 5}

Comparison of Speed Differences of Cars and Subject Vehicles in Cars-Only and Heterogeneous Traffic Conditions on $7.5 \mathrm{~m}$ Wide Road Space

\begin{tabular}{|c|c|c|c|c|c|c|}
\hline \multirow{2}{*}{$\begin{array}{c}\text { Volume- } \\
\text { to- } \\
\text { Capacity } \\
\text { (V/C) } \\
\text { Ratio }\end{array}$} & \multicolumn{6}{|c|}{ Speed Difference of Cars and Subject Vehicles in $\mathrm{km} / \mathrm{h}$} \\
\hline & $\begin{array}{c}\text { Cars-Only } \\
\text { Traffic }\end{array}$ & $\begin{array}{c}\text { Heterogeneous } \\
\text { Traffic }\end{array}$ & $\begin{array}{c}\text { Cars-Only } \\
\text { Traffic }\end{array}$ & $\begin{array}{c}\text { Heterogeneous } \\
\text { Traffic }\end{array}$ & $\begin{array}{c}\text { Cars-Only } \\
\text { Traffic }\end{array}$ & $\begin{array}{c}\text { Heterogeneous } \\
\text { Traffic }\end{array}$ \\
\hline \multicolumn{7}{|c|}{ Subject Vehicle: Bus } \\
\hline & \multicolumn{6}{|c|}{ Vehicle Composition } \\
\hline & \multicolumn{2}{|c|}{$2 \%$} & \multicolumn{2}{|c|}{$5 \%$} & \multicolumn{2}{|c|}{$10 \%$} \\
\hline 0.3 & 10.99 & 10.06 & 11.01 & 10.32 & 10.96 & 9.19 \\
\hline 0.5 & 10.17 & 7.95 & 9.91 & 7.52 & 9.92 & 6.95 \\
\hline 0.7 & 8.37 & 5.29 & 7.91 & 4.76 & 8.24 & 4.28 \\
\hline \multicolumn{7}{|c|}{ Subject Vehicle: L.C.V. } \\
\hline & \multicolumn{6}{|c|}{ Vehicle Composition } \\
\hline & \multicolumn{2}{|c|}{$2 \%$} & \multicolumn{2}{|c|}{$5 \%$} & \multicolumn{2}{|c|}{$10 \%$} \\
\hline 0.3 & 7.21 & 6.92 & 7.98 & 7.57 & 7.69 & 6.81 \\
\hline 0.5 & 6.39 & 4.30 & 7.47 & 4.54 & 7.49 & 4.84 \\
\hline 0.7 & 5.46 & 3.27 & 6.37 & 3.32 & 6.32 & 3.01 \\
\hline \multicolumn{7}{|c|}{ Subject Vehicle: M.Th.W. } \\
\hline & \multicolumn{6}{|c|}{ Vehicle Composition } \\
\hline & \multicolumn{2}{|c|}{$3 \%$} & \multicolumn{2}{|c|}{$9 \%$} & \multicolumn{2}{|c|}{$15 \%$} \\
\hline 0.3 & 18.86 & 17.06 & 19.23 & 16.82 & 19.01 & 16.02 \\
\hline 0.5 & 17.35 & 13.37 & 17.04 & 12.17 & 17.11 & 10.99 \\
\hline 0.7 & 14.68 & 7.50 & 14.45 & 6.04 & 14.69 & 5.14 \\
\hline \multicolumn{7}{|c|}{ Subject Vehicle: M.T.W. } \\
\hline & \multicolumn{6}{|c|}{ Vehicle Composition } \\
\hline & \multicolumn{2}{|c|}{$20 \%$} & \multicolumn{2}{|c|}{$40 \%$} & \multicolumn{2}{|c|}{$60 \%$} \\
\hline 0.3 & 10.19 & 8.74 & 10.30 & 8.11 & 10.10 & 7.82 \\
\hline 0.5 & 8.67 & 5.46 & 8.40 & 4.68 & 8.38 & 3.57 \\
\hline 0.7 & 6.18 & 0.16 & 6.03 & 0.03 & 5.96 & $-0.63^{*}$ \\
\hline
\end{tabular}

*Speed of cars less than the speed of M.T.W.

Bicycles are slow moving vehicles whose movement is confined to the left most $1.5 \mathrm{~m}$ width of the road space. It was observed during simulation that there is not much variation in the speed of the bicycles even when the traffic flow was increased to capacity level from low volume levels. In order to clearly depict the impact of change in composition of bicycles on the average speeds of cars in cars only and heterogeneous traffic conditions, it was decided to explain the reason for the trend in the variation of BPCU and PCU values of bicycles by taking into account the average car speeds for both the cases. At low volume levels, the presence of bicycles, with very low free speeds, may not become a severe deterrent in reducing the speed of the cars. Though significant speed difference exists between cars and bicycles at low volume levels, cars can perform overtaking maneuvers without much of reduction in their speeds. An increase in traffic volume at this stage significantly reduces the spacing between cars and bicycles resulting in a steep rate of reduction in the 
speed of cars as shown in Table 6. Also, it was found that cars were not able to make use of the space reserved for bicycles at higher volumes due to the presence of bicycles on that space causing severe impedance to the movement of cars. Hence, bicycles moving at lower speed hold higher BPCU value than a car moving at higher speed. At volume levels near capacity, the speed of the traffic as a whole, gets reduced and consequently, the speed difference between cars and bicycles get reduced resulting in the decreasing trend of the BPCU value of the bicycles.

\subsection{Check for Accuracy of Estimated PCU Values}

For the purpose of checking the accuracy of the PCU estimates for the different categories of vehicles, a comparison of the equivalent traffic flow in terms of PCU and in terms of number of passenger cars, pertaining to the road width of $7.5 \mathrm{~m}$ was done for a set of pre fixed V/C ratios. For this purpose, first, the cars-only traffic flow was simulated on $7.5 \mathrm{~m}$ wide road space and the road capacity was obtained as 3400 cars per hour by making the speed-flow curve. Then, the flows in cars per hour corresponding to a set of pre fixed $\mathrm{V} / \mathrm{C}$ ratios were determined through simulation. The check for the accuracy of the PCU estimates was done for all the chosen compositions of heterogeneous traffic by simulating the flow of heterogeneous traffic on the same road space, for the same set of $\mathrm{V} / \mathrm{C}$ ratio values (by taking the capacity value from the speed-flow curve developed corresponding to heterogeneous traffic on 7.5 $\mathrm{m}$ wide road space). For any case, by knowing the composition of the heterogeneous traffic, it is possible to calculate the number of vehicles of each category present in the traffic stream. The PCU values of the different vehicle categories, at the selected $\mathrm{V} / \mathrm{C}$ ratios can be obtained from Figs. 14 through 18 . Then, the number of vehicles in each category multiplied by the corresponding PCU value gives the PCU equivalents of each category of vehicles. The products, thus obtained, were summed up to get the total traffic flow of heterogeneous traffic in PCU per hour.

To explain the accuracy of estimates on statistical basis, paired $t$-test was performed for all the compositions of heterogeneous traffic flows considered in this study, by relating the flow in number of cars per hour, for the selected set of $\mathrm{V} / \mathrm{C}$ ratios, and the corresponding heterogeneous traffic flows expressed in PCU per hour. Based on the

\section{Table 6}

Comparison of Percentage Speed Reduction of Cars in Cars-Only and Heterogeneous Traffic Conditions on $7.5 \mathrm{~m}$ Wide Road

\begin{tabular}{|c|c|c|c|c|c|c|}
\hline \multirow{2}{*}{\begin{tabular}{|c|} 
Volume-to- \\
Capacity \\
(V/C) \\
Ratio \\
\end{tabular}} & \multicolumn{6}{|c|}{ Speed Reduction of Cars in Percentage } \\
\hline & $\begin{array}{c}\text { Cars-Only } \\
\text { Traffic }\end{array}$ & $\begin{array}{c}\text { Heterogeneous } \\
\text { Traffic }\end{array}$ & $\begin{array}{c}\text { Cars-Only } \\
\text { Traffic }\end{array}$ & $\begin{array}{c}\text { Heterogeneous } \\
\text { Traffic }\end{array}$ & $\begin{array}{c}\text { Cars-Only } \\
\text { Traffic }\end{array}$ & \begin{tabular}{|c} 
Heterogeneous \\
Traffic
\end{tabular} \\
\hline \multicolumn{7}{|c|}{ Subject Vehicle: Bicycle } \\
\hline & \multicolumn{6}{|c|}{ Vehicle Composition } \\
\hline & \multicolumn{2}{|c|}{$2 \%$} & \multicolumn{2}{|c|}{$6 \%$} & \multicolumn{2}{|c|}{$10 \%$} \\
\hline $0.5-0.7$ & 15.37 & 13.28 & 27.19 & 17.19 & 29.95 & 18.44 \\
\hline $0.7-0.9$ & 41.44 & 31.20 & 43.25 & 36.38 & 44.97 & 40.25 \\
\hline $0.9-1.0$ & 38.37 & 31.40 & 40.17 & 27.96 & 32.95 & 23.08 \\
\hline
\end{tabular}


results of the $t$-test, it was found that the estimated PCU values are accurate enough to represent the traffic flow in PCU per hour at $5 \%$ level of significance (95\% confidence limit). As example, the details of $t$-test conducted for the chosen base traffic composition, on $7.5 \mathrm{~m}$ wide road space are shown in Table 7. Based on the statistical test, it may be concluded that the estimated PCU values are accurate enough to represent the traffic flow in PCU per hour for all the compositions of heterogeneous traffic flows considered in this study.

\section{Conclusions}

The following are the important conclusions of the study:

a) The validation results of the simulation model of heterogeneous traffic flow indicate that the model is capable of replicating the heterogeneous traffic flow on mid block sections of urban roads to a highly satisfactory extent. The validity of the model is further confirmed by the logical trend of the speed-flow relationships developed, using the simulation model.

b) It is found that, under heterogeneous traffic conditions, for a given roadway condition and traffic composition, the PCU value of vehicles varies significantly with change in traffic volume and composition. Hence, it is desirable to treat PCU as dynamic quantity for the different vehicle categories.

c) It is found that, by virtue of the complex nature of interaction between vehicles under the heterogeneous traffic condition, at low volume levels, the PCU value of vehicles increases with increases in traffic volume, whereas under higher volume conditions, the PCU value decreases with increase in traffic volume, for any given composition.

d) It is found that the effect of traffic composition on PCU values is higher

\section{Table 7}

Statistical Test for PCU Values on $7.5 \mathrm{~m}$ Wide Road Space

\begin{tabular}{|c|c|c|c|c|c|}
\hline \multirow{2}{*}{$\begin{array}{c}\text { Volume-to- } \\
\text { Capacity } \\
\text { (V/C) } \\
\text { Ratio }\end{array}$} & \multicolumn{2}{|c|}{ Volume in PCU } & \multirow[b]{2}{*}{ Difference } & \multirow{2}{*}{$\begin{array}{l}\text { Deviation from } \\
\text { mean difference }\end{array}$} & \multirow{2}{*}{$\begin{array}{c}\text { Square of } \\
\text { Deviation from } \\
\text { mean difference }\end{array}$} \\
\hline & $\begin{array}{c}\text { Cars-Only } \\
\text { Traffic }\end{array}$ & $\begin{array}{c}\text { Heterogeneous } \\
\text { Traffic }\end{array}$ & & & \\
\hline 0.095 & 324 & 287 & 37 & -124 & 15376 \\
\hline 0.297 & 1010 & 987 & 23 & -110 & 12100 \\
\hline 0.495 & 1684 & 1796 & -112 & 25 & 625 \\
\hline 0.696 & 2365 & 2608 & -243 & 156 & 24336 \\
\hline 0.898 & 3054 & 3260 & -206 & 119 & 14161 \\
\hline \multirow[t]{2}{*}{1.000} & 3400 & 3421 & -21 & -66 & 4356 \\
\hline & & & $\Sigma-522$ & & 70954 \\
\hline \multicolumn{6}{|c|}{$\begin{array}{l}d_{\text {mean }}=\text { Mean of observed difference }=-522 / 6=-87 \\
t \text { statistic of traffic flows, } t_{o}=d_{\text {mean }} /\left(s_{d} / \sqrt{ } k\right) \text {, where } k=\text { Number of data sets }=6 \\
s_{d}^{2}=70954 /(k-1)=70954 /(6-1)=14190.8 \text {, where } s_{d} \text { is the standard deviation } \\
s_{d}=119.125 \\
\text { Therefore, }\left|t_{o}\right|=-87 /(119.125 / \sqrt{ } 6)=1.79 \\
\text { The critical value of } t \text { statistic for level of significance of } 0.05 \text { and } 5 \text { degrees of freedom, obtained from standard } \\
t \text {-distribution Table, is } 2.57 \text {. }\end{array}$} \\
\hline
\end{tabular}


at lower values and the effect of traffic composition on PCU values decreases with increase in the composition of subject vehicle.

e) The check performed to ascertain the accuracy of the PCU estimates by comparing the flow of cars-only traffic and the flow of heterogeneous traffic measured in terms of PCU equivalent for various compositions considered in this study indicate that, the estimates are fairly accurate.

\section{References}

Al-Kaisy, A.F.; Hall, F.L.; Reisman, E.S. 2002. Developing passenger car equivalents for heavy vehicles during queue discharge flow, Transportation Research Part A: Policy and Practice. DOI: http://dx.doi.org/10.1016/S09658564(01)00032-5, 36(8): 725-742.

Al-Kaisy, A.F.; Younghan, J.; Rakha, H. 2005. Developing passenger car equivalency factors for heavy vehicles during congestion, Journal of Transportation Engineering. DOI: http://dx.doi.org/10.1061/(ASCE)0733947X(2005)131:7(514), 131(7): 514-523.

Arasan, V.T.; Koshy, R. 2005. Methodology for modelling highly heterogeneous traffic flow, Journal of Transportation Engineering. DOI: http://dx.doi.org/10.1061/ (ASCE)0733-947X(2005)131:7(544), 131(7): 544-551.

Arasan, V.T.; Arkatkar, S.S. 2010. Micro-simulation study of effect of volume and road width on PCU of vehicles under heterogeneous traffic, Journal of Transportation Engineering. DOI: http://dx.doi.org/10.1061/(ASCE) TE.1943-5436.0000176, 136(12): 1110-1119.

Arasan, V.T.; Krishnamurthy, K. 2008. Effect of Traffic Volume on PCU of Vehicles under Heterogeneous Traffic Conditions, Road and Transport Research, 17(1): 32-49.

Bains, M.S.; Ponnu, B.; Arkatkar, S.S. 2012. Modeling of Traffic Flow on Indian Expressways using Simulation
Technique, Procedia - Social and Behavioral Sciences. DOI: http://dx.doi.org/10.1016/j.sbspro.2012.04.121, 43: 475-493.

Banks, J.; Carson, J.S.; Nelson, B.L.; Nicol, D.M. 2004. Discrete-event system simulation. Pearson Education, Singapore. $3 \mathrm{p}$.

Chandra, S.; Sikdar, P.K. 2000. Factors affecting PCU in mixed traffic situations on urban roads, Road and Transport Research, 9(3): 40-50.

Craus, J.; Polus, A.; Grinberg, I. 1980. A revised method for the determination of PCE, Transportation Research Part A: General. DOI: http://dx.doi.org/10.1016/01912607(80)90040-0, 14(4): 241-246.

Elefteriadou, L.; Torbic, D.; Webster, N. 1997. Development of PCE for freeways, two-lane highways and arterials, Transportation Research Record: Journal of the Transportation Research Board. DOI: http://dx.doi. org/10.3141/1572-07, 1572: 51-58.

Fan, H.S.L. 1990. Passenger car equivalents for vehicles on Singapore expressways, Transportation Research Part A: General. DOI: http://dx.doi.org/10.1016/01912607(90)90051-7, 24(5): 391-396.

Geistefeldt, J. 2009. Estimation of Passenger Car Equivalents Based on Capacity Variability, Transportation Research Record: Journal of the Transportation Research Board. DOI: http://dx.doi.org/10.3141/2130-01, 2130: 1-6.

Indian Roads Congress. 1990. Guidelines for Capacity of Urban Roads in Plain Areas, IRC: 106-1990, New Delhi, India. $10 \mathrm{p}$.

Justo, C.E.G.; Tuladhar, S.B.S. 1984. Passenger car unit values for urban roads, Journal of Indian Roads Congress, 45(1): 183-238.

Krammes, R.A.; Crowley, K.W. 1986. Passenger car equivalents for trucks on level freeway segments, Transportation Research Record, 1091: 10-17. 
Kumar, V.M.; Rao, S.K. 1996. Simulation Modeling of Traffic Operations on Two Lane Highways, Highway Research Bulletin, 54: 211-237.

Mallikarjuna, C.; Rao, R.K. 2006. Modeling of Passenger Car Equivalency under Heterogeneous Traffic Conditions. In Proceedings of the Research into Practice: 22nd Australian Road Research Board (ARRB) Conference. 1-13.

Marwah, B.R.; Singh, B. 2000. Level of Service Classification for Urban Heterogeneous Traffic: A Case Study of Kanpur Metropolis. In Transportation Research Circular E-C018: Proceedings of the 4th International Symposium on Highway Capacity. 271-286.

Ramanayya, T.V. 1988. Highway capacity under mixed traffic conditions, Traffic Engineering and Control, 29(5): 284-287.
Rongviriyapanich, T.; Suppattrakul, C. 2005. Effects of motorcycles on traffic operations on arterial streets, Journal of Eastern Asia Society for Transportation Studies, 6: 137-146.

Transport and Road Research Laboratory (TRRL). 1965. Research on Road Traffic, H.M.S.O, London.

Webster, N.; Elefteriadou, L. 1999. A simulation study of truck passenger car equivalents (PCE) on basic freeway sections, Transportation Research Part B: Methodological. DOI: http://dx.doi.org/10.1016/S0965-8564(98)000366, 33(5): 323-336.

Werner, A.; Morrall, J.F. 1976. Passenger car equivalencies of trucks, buses and recreational vehicles for two-lane rural highways, Transportation Research Record, 615: 10-17 